
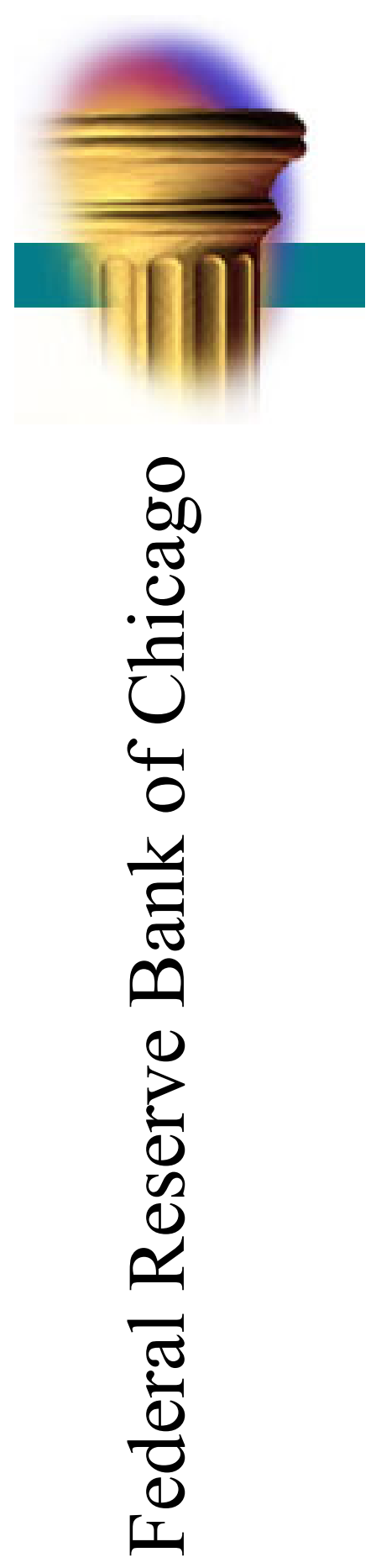

\title{
The limits of forward guidance
}

Jeffrey R. Campbell, Filippo Ferroni, Jonas D. M. Fisher, and Leonardo Melosi

\section{March 20, 2019}

\section{WP 2019-03}

https://doi.org/10.21033/wp-2019-03

${ }^{*}$ Working papers are not edited, and all opinions and errors are the responsibility of the author(s). The views expressed do not necessarily reflect the views of the Federal Reserve Bank of Chicago or the Federal Reserve System. 


\title{
The limits of forward guidance*
}

\author{
Jeffrey R. Campbell ${ }^{\dagger}$ \\ Jonas D. M. Fisher
}

\author{
Filippo Ferroni \\ Leonardo Melosi
}

March 20, 2019

\begin{abstract}
The viability of forward guidance as a monetary policy tool depends on the horizon over which it can be communicated and its influence on expectations over that horizon. We develop and estimate a model of imperfect central bank communications and use it to measure how effectively the Fed has managed expectations about future interest rates and the influence of its communications on macroeconomic outcomes. Standard models assume central banks have perfect control over expectations about the policy rate up to an arbitrarily long horizon and this is the source of the so-called "forward guidance puzzle." Our estimated model suggests that the Fed's ability to affect expectations at horizons that are sufficiently long to give rise to the forward guidance puzzle is substantially limited. We also find that imperfect communication has a significant impact on the propagation of forward guidance. Finally, we develop a novel decomposition of the response of the economy to forward guidance and use it to show that empirically plausible imperfect forward guidance has a quantitatively important role bringing forward the effects of future rate changes and that poor communications have been a source of macroeconomic volatility.
\end{abstract}

JEL Classification Numbers: E0

Keywords: monetary policy, forward guidance puzzle, central bank communication, business cycles, risk management

*The views expressed herein are the authors' and do not necessarily represent those of the Federal Reserve Bank of Chicago or the Federal Reserve System.

${ }^{\dagger}$ All authors Federal Reserve Bank of Chicago. In addition Campbell is affiliated with CentER, Tilburg University, and Melosi is affiliated with the European University Institute and the CEPR. E-mail addresses are: jcampbell@frbchi.org; jfisher@frbchi.org; fferroni@frbchi.org; lmelosi@frbchi.org. 


\section{Introduction}

Since the onset of the financial crisis informing the public about its future intentions has become central to Fed communications. Even before the crisis post-meeting statements and speeches by Fed officials included forward-looking language intended to clarify its intentions

about policy in the future. Such communications have become known as forward guidance. The Fed's forward guidance during the period in which the policy rate was at its effective lower bound (ELB) is widely viewed to have been explicitly designed to lower expectations of future short term rates. By doing so far enough into the future such communications may have had a material effect on the interest rates that govern longer term investment projects and boosted economic activity more broadly.

This mechanism is present within the standard New Keynesian (NK) framework. In NK models forward guidance allows the central bank to influence private-sector expectations about future interest rates and thereby to potentially improve macroeconomic outcomes. However the practical viability of this policy tool ultimately depends on the horizon over which the Fed is able to influence expectations and the power of its communications to influence expectations within that horizon. In this paper we develop an empirically tractable NK model with central bank communications and use it to measure how effectively the Fed has influenced private-sector expectations about future interest rates and the macroeconomic consequences of this influence over the period 1993-2016.

Standard NK models assume the central bank has perfect control over private-sector expectations about the policy rate up to an arbitrarily long horizon. Eggertsson and Woodford (2003) and Krugman (1998) rely on this assumption to formulate policies to combat the severe consequences of monetary policy being constrained by the ELB. However, such perfect control gives rise to implausible implications. In particular it is the source of the "forward guidance puzzle" highlighted in an empirical context by Del Negro, Giannoni, and Patterson (2015). The forward guidance puzzle arises from a theoretical implication common to all standard NK models: the near term effects of a commitment to maintain an interest rate peg for an additional period increases without bound with the horizon of the peg. This is clearly implausible and so it has inspired a large and growing literature exploring modifications to 
the NK framework that dampen the effects of forward guidance as traditionally conceived. ${ }^{1}$

The ultimate source of the effects of forward guidance in standard NK models and most of the proposed modifications to dampen those effects is the assumption that the central bank can communicate to the public clear and credible commitments to particular interest rate paths. Is it plausible that the central bank has the ability to conduct such communications? If there are failures to communicate clearly and credibly what are their implications for the conduct of policy? Our framework allows us to address these questions. Consistent with the previous literature we conceive of forward guidance as communications about future deviations from the central bank's policy rule. The central bank cannot perfectly communicate these deviations in advance but instead is limited to sending noisy signals about them. The public's expectations are influenced as they learn from the signals about what the policy deviations actually will be.

We view the noise in the signals as reflecting two key challenges to the communication of forward guidance. The most obvious challenge is that the words used by central bankers may confuse the public. One example is the "taper tantrum" episode when bond markets seemingly over-reacted to remarks by Chairman Bernanke in May 2013 about winding down the Fed's bond purchases. This reaction was puzzling to many observers since earlier Fed communications should had prepared markets for this eventuality. Another challenge is that the central bank simply does not know how it might want to deviate from its established rule in the future. For example, the policy rule assumed in standard models does not address risk management. Even when the policy rate is far from the ELB central banks might want to deviate from their implicit rules to guard against risks to the economic outlook. The history of Fed communications is replete with examples of such behavior. ${ }^{2}$

We reach conclusions about central bank communications by embedding our communications framework within a medium-scale NK model estimated using a rich array of macroeco-

\footnotetext{
${ }^{1}$ Key contributions include Del Negro et al. (2015) who emphasize finite lifetimes, Gabaix (2016) and Angeletos and Lian (2018) who consider bounded rationality, McKay, Nakamura, and Steinsson (2015) and Hagedorn, Luo, Manovskii, and Mitman (2019) who study incomplete markets, Campbell, Fisher, Justiniano, and Melosi (2017) who focus on preferences for government bonds, Campbell and Weber (2019) who study imperfect credibility, Farhi and Werning (2017) who explore the interaction of bounded rationality and incomplete markets, and Kaplan, Moll, and Violante (2018) who study agent heterogeneity.

${ }^{2}$ See Evans, Fisher, Gourio, and Krane (2015) for examples of risk management considerations in statements and minutes of the Federal Open Market Committee.
} 
nomic data. An important feature of our empirical strategy is that expected future interest rates in our model and our estimates of forward guidance reconcile data on aggregate activity and interest rate futures. Our estimated model suggests that the Fed's ability to affect expectations at horizons that are sufficiently long to give rise to the forward guidance puzzle is substantially limited. The difficulties inherent in communicating complicated decisions about the future path of interest rates may be too great for forward guidance to be the powerful tool predicted by standard NK models. We also find that imperfect communications heavily influence the propagation of monetary shocks. The response of the economy to a shock that changes the anticipated path of policy deviations is delayed and has greater amplitude when communications are imperfect compared to when they are not.

We use our estimated model to construct a novel decomposition of the dynamic effects of forward guidance into the part solely due to the change in expectations it triggers and the effects that arise from a scenario in which the central bank opts not to communicate its future policy deviations. This decomposition allows us to establish two results. First, private sector expectations of future policy deviations pull forward the effects of those deviations significantly compared to not communicating at all. We argue that this suggests forward guidance, even if it is imperfectly communicated, could be a valuable tool for a central bank seeking to guard against perceived risks to the economic outlook. Second, unintended communication that contains no information about future policy deviations leads to sizable macroeconomic volatility. This result highlights the benefits that might accrue to a central bank that invests in developing effective communications. It also helps to explain why central bankers are typically wary of what they say in public.

Our analysis exploits the observational equivalence established by Chahrour and Jurado (2018). In particular there is an observationally equivalent version of our model in which the central bank perfectly communicates news about future interest rates. The literature thus far has almost exclusively modeled forward guidance as news. News consists of the central bank perfectly communicating future deviations from the policy rule which are known to be subject to revisions at later dates. Why focus on signal extraction rather than a model with news? The news representation is easier to estimate and we exploit that fact here. However, if one then wants to use the estimated model to evaluate the effectiveness of forward 
guidance as a policy tool, our model of central bank communications seems more appropriate. The reason is that by focusing on news shocks one abstracts from how effectively central bank announcements affect private expectations. Our model addresses the communications challenges inherent in forward guidance and allows us to shed light on the ability of the central bank to exploit forward guidance. Of course observational equivalence means that the data cannot select one approach over the other. Nevertheless the signaling approach seems better suited to interpreting the evolution of expectations and therefore the nature of the communications challenges faced by central banks.

The importance of communications in the transmission of monetary policy has long been acknowledged. For example, Woodford (2003) emphasizes that successful monetary policy is not so much a matter of effective control of overnight interest rates as it is the shaping of market expectations about how interest rates, inflation, and output evolve in the future. One of our objectives is to evaluate the Fed's ability to shape these expectations. There are several papers that study the central bank's ability to shape expectations. These papers are primarily theoretically oriented and generally eschew quantitative implications. Two key contributions are Eusepi and Preston (2010) and Andrade, Gaballo, Mengus, and Mojon (2018). The former develop a model with learning to study the link between central bank communication and the anchoring of inflation expectations. The latter study the normative implications of forward guidance in a NK model where agents have heterogeneous beliefs about the strength of the central bank's commitment.

There are a few papers that use structural models to study the quantitative implications of forward guidance. Campbell et al. (2017) use a medium scale NK framework along the lines of Christiano, Eichenbaum, and Evans (2005) and Smets and Wouters (2007) to quantify the macroeconomic effects of forward guidance after the onset of the Great Recession. Their analysis focuses on news about future interest rates and therefore has little to say about the ability of the central bank to communicate its future intensions. Bianchi and Melosi (2017) use a NK model to evaluate the welfare implications of forward looking communications. Their empirical framework is not as rich as ours and in particular does not exploit the information contained in market expectations of future interest rates which is central to our analysis. Finally, Nakamura and Steinsson (2018) develop a stylized NK model which they 
use to estimate the strength of Delphic forward guidance as defined by Campbell, Evans, Fisher, and Justiniano (2012). None of the papers in this literature empirically evaluate the central bank's ability to steer private-sector expectations at different horizons.

Another related line of research uses stylized models to draw normative conclusions about how the central bank should communicate. Morris and Shin (2002) introduce a class of models with dispersed information to study the effects of central bank communications. They show that policy communication may hinder social welfare if private information is sufficiently accurate. Angeletos and Pavan (2007) show that this result emerges only under particular assumptions about the kind of externalities assumed in the payoff structure. Melosi (2016) examines the quantitative implications of the kind of communications highlighted in this theoretical work. In contrast to our focus on forward guidance this literature emphasizes communications about current conditions.

Our work is also related to the reduced form empirical literature launched by Kuttner (2001) which uses event studies to identify unexpected FOMC policy actions and their effects on macroeconomic outcomes and asset prices. Gürkaynak, Sack, and Swanson (2005) extended that methodology to identify forward guidance shocks which leave the current policy rate unchanged while impacting current expectations of its future values. They found substantial impacts of near-term (one to six quarters out) forward guidance shocks on two, five, and ten year Treasury bond yields. Campbell, Evans, Fisher, and Justiniano (2012) verified that this pattern continued while the FOMC set its policy rate at the ELB. The large and growing event study literature has not settled on an interpretation of these long horizon effects. Our analysis strongly suggests that they are not due to the ability of the Fed to shape expectations over such long horizons.

The remainder of the paper begins by presenting the central bank communications environment. We then describe the fully-specified model in which we embed this environment and our estimation of the model. Next we present two sets of findings derived from the estimated model. First we discuss the information flows implied by our estimates. Second we discuss the propagation of forward guidance shocks under various assumptions about communication. The last section offers some concluding remarks. 


\section{Central bank communications}

The central bank sets the date $t$ interest rate on one-period government bonds, $R_{t}$, according to

$$
R_{t}=g_{t}\left(R_{t-1}, \pi_{t}^{g a p}, y_{t}^{g a p}\right)+\theta_{t}
$$

where $g_{t}$ is the possibly time-varying policy rule which depends on the lagged policy rate and the central bank's measures of the inflation and output gaps, $\pi_{t}^{g a p}$ and $y_{t}^{g a p}$. Deviations of the policy rate from the rule, $\theta_{t}$, are exogenous, stationary, and zero mean Gaussian random variables. We allow them to be serially correlated up to the $H$-th lag. This is to be consistent with evidence of serially correlated deviations from estimated policy rules and evidence that changes in interest rate futures before and after the release of FOMC statements are correlated across their term structure. The private sector observes $R_{t}$ and understand that policy is set according to (1). Finally, the central bank perfectly communicates to agents the policy rule $g_{t}$ and its measures of the gaps.

The policy deviations are central to our analysis. They capture two key aspects of monetary policy that the central bank may want to implement contemporaneously or communicate about in advance. During "normal times" when the policy rate is relatively far from the ELB they represent the central bank implementing a modestly different policy than what its rule would otherwise stipulate, along the lines discussed by Leeper and Zha (2003) and Laséen and Svensson (2011). ${ }^{3}$ A natural interpretation of these deviations is that they capture risk management behavior by the central bank. That is, its responses to changes it perceives in the risk environment. In the linearized model we study below risk has no impact on agents' decisions. Yet the interest rate futures data we use to estimate the model embed responses by the Fed to changes in risk. To the extent that the changes it responds to are orthogonal to other shocks that drive fluctuations and their responses to them are systematic our assumptions about the deviations do not seem particularly restrictive. The other key aspect of monetary policy the deviations capture is actions when the policy rate is near the ELB or the rule stipulates that the policy rate should be negative. To some extent these actions are

\footnotetext{
${ }^{3}$ We use the modifier "modestly" to indicate that the deviations from the rule are not sufficiently large to lead agents to change their view that the central bank is committed to the policy rule $g_{t}$.
} 
similar to risk management. But they also incorporate the Krugman-Eggertson-Woodford policy of keeping rates "lower for longer." This policy is wrapped up with forward guidance.

Forward guidance consists of communicating to the private sector about future deviations of the policy rate from the rule up to $H$ periods ahead, $\theta_{t+h}, h=0,1,2, \ldots, H$. Communication at date $t$ consists of sending an $(H+1) \times 1$ vector of noisy signals $s_{t}=\left[s_{t}^{h}\right]$ about the future deviations $\boldsymbol{\theta}_{t}=\left[\theta_{t+h}\right]$. The signals are specified as:

$$
s_{t}=\boldsymbol{\theta}_{t}+v_{t}
$$

where the vector $v_{t}=\left[v_{t}^{h}\right]$ denotes noise. The noise is Gaussian with mean zero and variancecovariance matrix $\Xi_{v}$.

Since agents observe current and lagged policy rates as well as the central bank's gaps they observe $\theta_{t}$ as well so that $v_{t}^{0}=0$. The remaining noise should be interpreted as comprising two components. The first component represents the central bank's imperfect knowledge about what it will do in the future. For example, unforseen events such as the near failure of Long-Term Capital Management in September 1998 or the onset of the First Gulf War in January 2001 led the Fed to reassess risks to the macroeconomic outlook and lower the federal funds rate seemingly below the level indicated by its contemporaneous measures of the output and inflation gaps. The second component represents miscommunication to the private sector about the central bank's true intentions.

The private sector observes the signals, know the stochastic processes governing $\boldsymbol{\theta}_{t}$ and $v_{t}$, and update their beliefs about $\boldsymbol{\theta}_{t}$ in a Bayesian fashion. The Gaussian structure of the shocks implies that it is optimal for agents to update their expectations of policy deviations using the Kalman filter. Specifically, expectations following the release of date $t$ signals are updated as

$$
E_{t} \boldsymbol{\theta}_{t}=E_{t-1} \boldsymbol{\theta}_{t}+\kappa \cdot\left(s_{t}-E_{t-1} \boldsymbol{\theta}_{t}\right)
$$

where

$$
\kappa=\Xi_{\theta}\left[\Xi_{\theta}+\Xi_{v}\right]^{-1}
$$

is the Kalman gain and $\Xi_{\theta}$ denotes the time-invariant variance-covariance matrix of current 
and future deviations from the rule, $\boldsymbol{\theta}_{t}$, conditional on receiving signals up to date $t-1$, i.e. $\Xi_{\theta}$ is the variance-covariance matrix of $\boldsymbol{\theta}_{t}-E_{t-1} \boldsymbol{\theta}_{t}$.

The conditional variance-covariance matrix $\Xi_{\theta}$ is time-invariant because the agents' signal extraction problem is stationary. To see this notice that in every period $t$ agents have received one signal about the $H$-period-ahead deviation $\theta_{t+H}$; two signals about the $(H-1)$-period-

ahead deviation $\theta_{t+H-1}$ (one today and the other yesterday), and so on. Given that we assume the noise is stationary, it follows that the horizon of each central bank announcement is a sufficient statistic for tracking agents' beliefs about $\theta_{t+h}$ over time. Therefore the variancecovariance matrix of the vector of deviations $\boldsymbol{\theta}_{t}$ conditional on publicly available information at date $t-1$ is time-invariant. ${ }^{4}$

\section{General equilibrium model}

Our empirical investigation of the communication of forward guidance involves embedding the communications environment just described within Campbell et al. (2017)'s mediumscale NK model. Since much of the model is familiar and described in their paper our discussion here is brief and emphasizes the model's shocks and other key features that are integral to our measurement of forward guidance.

\subsection{Households}

The economy consists of a large number of identical, infinitely lived households with preferences described by the lifetime utility function

$$
E_{0} \sum_{t=0}^{\infty} \beta^{t}\left[\varepsilon_{t}^{b} \frac{\left[\left(C_{t}-\varrho \bar{C}_{t-1}\right)\left(1-\vartheta H_{t}^{1+\gamma_{H}}\right)\right]^{1-\gamma_{C}}-1}{1-\gamma_{C}}+\varepsilon_{t}^{s} L\left(\frac{B_{t+1}}{P_{t} R_{t}}\right)\right], \gamma_{C}, \gamma_{H}, \varrho>0
$$

Here $C_{t}$ denotes the household's consumption purchased in the competitive final goods market at nominal price $P_{t}, \bar{C}_{t}$ denotes aggregate per capita consumption (which equals $C_{t}$ in

\footnotetext{
${ }^{4}$ In principle one would like a communications framework with time-varying second as well as first moments. In the linearized general equilibrium model we study second moments have no impact on agents' decisions. From this perspective not having them be time-varying is inconsequential. Nevertheless having time-varying second moments could influence our estimates of forward guidance. Our approach seems like a sensible first step.
} 
equilibrium) and $H_{t}$ denotes hours worked. ${ }^{5}$ We set $\vartheta$ to normalize hours to equal 1 in steady state. The argument of the increasing and concave function $L, B_{t+1} /\left(P_{t} R_{t}\right)$, is the consumption value of one-period nominal government bonds purchased by the household at date $t$ and carried into date $t+1, B_{t+1}$.

The discount factor shock $\varepsilon_{t}^{b}$ has been shown by Justiniano, Primiceri, and Tambalotti (2010a) and others to be a key driver of consumption fluctuations. Eggertsson and Woodford (2003) and many others use this shock to drive the policy rate to the ELB and so it is particularly relevant for our analysis. We assume $\varepsilon_{t}^{b}$ evolves according to the stationary process given by

$$
\ln \varepsilon_{t}^{b}=\rho_{b} \ln \varepsilon_{t-1}^{b}+\eta_{t}^{b}, \eta_{t}^{b} \sim N\left(0, \sigma_{b}^{2}\right)
$$

Including preferences for government bonds has important implications for our measurement. ${ }^{6}$ First, they allow for an empirically plausible spread between interest rates on private and government bonds that is otherwise absent. Second, as discussed by Campbell et al. (2017) and Fisher (2015), the interest rate spread brings discounting into the household's linearized inter-temporal Euler equation for consumption. This discounting mitigates the forward guidance puzzle. Finally, Fisher (2015) shows the exogenous shock to these preferences, $\varepsilon_{t}^{s}$, provides a simple micro-foundation for Smets and Wouters (2007)'s ad hoc shock to the consumption Euler equation. This shock is crucial to the identification of empirical NK models since it is one of the few sources of co-movement between consumption, investment and hours. We assume the liquidity preference shock to the preference for "safe and liquid" government bonds, $\varepsilon_{t}^{s}$, evolves according to the stationary process given by

$$
\ln \varepsilon_{t}^{s}=\left(1-\rho_{s}\right) \varepsilon_{*}^{s}+\rho_{s} \ln \varepsilon_{t-1}^{s}+\eta_{t}^{s}, \eta_{t}^{s} \sim N\left(0, \sigma_{s}^{2}\right)
$$

The parameter $\varepsilon_{*}^{s}$ determines the steady state spread between the rates of return on government and private bonds.

\footnotetext{
${ }^{5}$ Campbell et al. (2017) work with a more general specification of preferences. It turns out that this generality is not important for our empirical results and so we abstract from it here.

${ }^{6}$ These preferences were first introduced into an empirical NK model by Campbell et al. (2017). Krishnamurthy and Vissing-Jorgensen (2011) used them to study the market for government securities. They are beginning to get wider attention in the literature. See, for example, Auclert, Rognlie, and Straub (2018) and Michaillat and Saez (2018).
} 
Households own the installed capital stock $K_{t}$ which they accumulate using the technology

$$
K_{t+1}=\left[1-\delta\left(U_{t}\right)\right] K_{t}+\varepsilon_{t}^{i}\left[1-S\left(\frac{I_{t}}{q_{t} I_{t-1}}\right)\right] I_{t}
$$

where $I_{t}$ denotes gross investment purchased from investment good producers described below and $S$ is an adjustment cost function that has the usual properties. The term $q_{t}$, defined below, corresponds to the growth rate of investment's stochastic trend. The owners of installed capital control the intensity with which it is utilized, $U_{t}$, so that the effective supply of capital services in period $t$ is $K_{t}^{e}=U_{t} K_{t}$. Increasing capacity utilization induces faster depreciation via the function $\delta$ which we specify as in Campbell et al. (2017). The technology for transforming investment goods into installed capital is subject to the shock $\varepsilon_{t}^{i}$. We assume this investment-demand shock evolves according to the stationary process given by

$$
\ln \varepsilon_{t}^{i}=\rho_{i} \ln \varepsilon_{t-1}^{i}+\eta_{t}^{i}, \eta_{t}^{i} \sim N\left(0, \sigma_{i}^{2}\right)
$$

Justiniano, Primiceri, and Tambalotti (2010b) find that this shock explains a substantial fraction of business cycle fluctuations in investment.

\subsection{Goods and labor markets}

Final goods are produced using differentiated intermediate inputs with the usual DixitStiglitz technology that is subject to shocks to the elasticity of substitution. Intermediate goods producers are monopolistic competitors who maximize profits subject to a standard Calvo pricing scheme with indexing. This and the shocks to the elasticity of substitution translate to a price mark-up shock, $\lambda_{t}^{p}$, which evolves according to the stationary process given by

$$
\ln \lambda_{t}^{p}=\left(1-\rho_{p}\right) \ln \lambda_{*}^{p}+\rho_{p} \ln \lambda_{t-1}^{p}-\phi_{p} \eta_{t-1}^{p}+\eta_{t}^{p}, \eta_{t}^{p} \sim N\left(0, \sigma_{p}^{2}\right)
$$

The parameter $\lambda_{*}^{p}$ denotes the steady state mark-up. Notice that we allow for innovations to price markups to be a first-order moving average process. 
Intermediate goods producer $i$ produces its output $Y_{i t}$ using the technology:

$$
Y_{i t}=\left(K_{i t}^{e}\right)^{\alpha}\left[A_{t}^{Y} H_{i t}\right]^{1-\alpha}-A_{t} \Phi, \alpha \in(0,1), \Phi>0
$$

where $H_{i t}$ is labor purchased at consumption wage $W_{t}$ in a competitive market and $\Phi$ is a fixed cost of production in units of the final good. The term $A_{t}^{Y}$ is the level of the neutral technology. This is a non-stationary process with growth rate $\nu_{t} \equiv \ln \left(A_{t}^{Y} / A_{t-1}^{Y}\right)$ that evolves according to the stationary process given by

$$
\nu_{t}=\left(1-\rho_{\nu}\right) \nu_{*}+\rho_{v} \nu_{t-1}+\eta_{t}^{\nu}, \eta_{t}^{\nu} \sim N\left(0, \sigma_{\nu}^{2}\right)
$$

where $\nu_{*}$ is the steady state growth rate of the neutral technology. We refer to $\nu_{t}$ as the neutral technology shock. The term $A_{t}$ in (5) is the stochastic trend of equilibrium consumption and output measured in consumption units which equals $A_{t}^{Y}\left(A_{t}^{I}\right)^{\alpha /(1-\alpha)}$, where $A_{t}^{I}$ is the level of the investment-specific technology described below with log growth rate denoted $\omega_{t}$. The $\log$ growth rate of $A_{t}$ is $z_{t}=\nu_{t}+\alpha \omega_{t} /(1-\alpha)$.

Perfectly competitive firms produce the investment goods supplied to households using a linear technology that transforms final goods into investment goods at rate $A_{t}^{I}$. The growth rate of $A_{t}^{I}$, which we call the investment-specific technology shock evolves according to the stationary process given by

$$
\omega_{t}=\left(1-\rho_{\omega}\right) \omega_{*}+\rho_{\omega} \omega_{t-1}+\eta_{t}^{\omega}, \eta_{t}^{\omega} \sim N\left(0, \sigma_{\omega}^{2}\right)
$$

The parameter $\omega_{*}$ is the mean growth rate of the investment-specific technology. In equilibrium investment has a stochastic trend with $\log$ growth rate $q_{t}=\nu_{t}+\omega_{t} /(1-\alpha)$.

We adopt Smets and Wouters (2007)'s approach to modeling the labor market when preferences are non-separable in consumption and labor. This approach involves Calvo-style sticky wages with a wage mark-up shock. We assume this shock, $\lambda_{t}^{w}$, follows a stationary process similar to $\lambda_{t}^{p}$ :

$$
\ln \lambda_{t}^{w}=\left(1-\rho_{w}\right) \ln \lambda_{*}^{w}+\rho_{w} \ln \lambda_{t-1}^{w}-\phi_{w} \epsilon_{t-1}^{w}+\eta_{t}^{w}, \eta_{t}^{w} \sim N\left(0, \sigma_{w}^{2}\right)
$$




\subsection{Central bank and government}

The central bank sets its policy rate, communicates with the public, and the public updates is expectations about policy deviations in the way described in Section 2. Our parametric specification of the monetary policy rule in (1) is

$$
g_{t}\left(R_{t-1}, \pi_{t}^{g a p}, y_{t}^{g a p}\right)=\rho_{R} \ln R_{t-1}+\left(1-\rho_{R}\right) \ln R_{t}^{n}, \rho_{R} \in[0,1)
$$

where $R_{t}^{n}$ is the notional target interest rate given by

$$
\ln R_{t}^{n}=\ln r_{*}+\ln \pi_{t}^{*}+\psi_{1} \pi_{t}^{g a p}+\psi_{2} y_{t}^{g a p}, \psi_{1}, \psi_{2}>0
$$

The constant $r_{*}$ corresponds to the steady state real interest rate on government bonds and $\pi_{t}^{*}$ is an exogenous inflation drift shock that could be interpreted as the central bank's intermediate target for inflation.

The drift term is included in the rule to address inflation's low-frequency movements during our sample. Since we have assumed the policy rule is perfectly communicated to the public so is $\pi_{t}^{*}$. Clearly this is not an innocuous assumption since the drift influences agents' inflation expectations and the Fed's communications about its inflation objectives were almost surely imperfect over much of the sample period we study. The inflation drift shock evolves according to the stationary process

$$
\ln \pi_{t}^{*}=\left(1-\rho_{\pi}\right) \pi_{*}+\rho_{\pi} \ln \pi_{t-1}^{*}++\eta_{t}^{\pi}, \eta_{t}^{\pi} \sim N\left(0, \sigma_{\pi}^{2}\right)
$$

where $\pi_{*}$ is steady state inflation.

The gaps in the policy rule are four-quarter moving averages of variables observed by private agents. We assume the central bank measures the inflation gap using the deviation of inflation from the contemporaneous value of the drift term:

$$
\pi_{t}^{g a p}=\frac{1}{4} E_{t} \sum_{j=-2}^{1}\left(\ln \pi_{t+j}-\ln \pi_{t}^{*}\right)
$$

It measures the output gap using the difference between the log level of aggregate output 
and its stochastic trend:

$$
y_{t}^{g a p}=\frac{1}{4} E_{t} \sum_{j=-2}^{1}\left(\ln Y_{t+j}-\ln y^{*}-\ln A_{t+j}\right) .
$$

The constant $y_{*}$ denotes steady state output. This is included to ensure that both gaps are closed in steady state with the nominal interest rate on government bonds $R_{*}=r_{*} \pi_{*}$.

The government issues bonds $B_{t+1}$ and collects lump sum taxes to pay for government spending $A_{t} g_{t}$ purchased in the final goods market. We assume the government balances its budget every period and has no legacy debt, so government bonds are in zero net supply. The government spending shock $g_{t}$ evolves according to the stationary process

$$
\ln g_{t}=\left(1-\rho_{g}\right) \ln s_{*}^{g}+\rho_{g} \ln g_{t-1}+\eta_{t}^{g}, \eta_{t}^{g} \sim N\left(0, \sigma_{g}^{2}\right),
$$

where $s_{*}^{g}$ is the government's share of output in steady state.

\subsection{Equilibrium}

Equilibrium is defined in the usual way and is described in more detail in Campbell et al. (2017). We study the solution to the log linearized equilibrium conditions of the detrended economy and apply econometric techniques that rely on linearity to estimate parameters and to study central bank communications. One may question how such an approach can be squared with the ELB. Without forward guidance it is possible that at some dates agents' expectations of future policy rates would violate the ELB constraint even if the contemporaneous rate did not. We use data on expected future funds rates, which of course do not violate the ELB, in our list of observables when we estimate our model. Forward guidance gives our model the flexibility to fit these data and thereby respect the ELB.

\section{Estimation}

Chahrour and Jurado (2018) show that models like ours can be represented in two observationally equivalent ways. We refer to our description of the model thus far as the signal 
representation. ${ }^{7}$ The observationally equivalent news representation has the central bank perfectly communicating news about future policy deviations. The news representation is easier to solve. Therefore, we estimate the news representation and use the mapping from the news representation to the signal representation to identify the key communications parameters $\Xi_{\theta}$ and $\Xi_{v}$. This approach is similar to Blanchard, L'Huillier, and Lorenzoni (2013).

We first describe how to derive the news representation and use it to identify $\Xi_{\theta}$ and $\Xi_{v}$. Then we show how we estimate the news representation. Our estimation strategy follows Campbell et al. (2017) quite closely and so our discussion of it is brief and emphasizes the key differences. The most important difference is that we confront evidence that both economic growth and interest rates on government bonds have declined over our sample period. Finally, we discuss briefly the properties of the estimated model.

\subsection{The news representation}

Let $\varepsilon_{R, t}^{h}$ denote news about the policy deviation $h$ periods hence revealed to the public through the policy signals at date $t, s_{t}$. By the definition of news

$$
\varepsilon_{R, t}^{h}=E_{t} \theta_{t+h}-E_{t-1} \theta_{t+h} .
$$

Collect news about policy deviations up to $H$ periods ahead in the vector $\varepsilon_{R, t}$ so that we have

$$
\boldsymbol{\varepsilon}_{R, t}=E_{t} \boldsymbol{\theta}_{t}-E_{t-1} \boldsymbol{\theta}_{t}
$$

In the signal representation the date $t$ revisions of private sector expectations about future policy deviations are given by equation (3). Combining equations (3) and (6) leads to the critical link between our model of central bank communications and news:

$$
\kappa\left(\boldsymbol{\theta}_{t}+v_{t}-E_{t-1} \boldsymbol{\theta}_{t}\right)=\boldsymbol{\varepsilon}_{R, t} .
$$

The forecast errors of policy deviations for each $h=0,1, \ldots, H$ periods ahead are related

\footnotetext{
${ }^{7}$ Chahrour and Jurado (2018) use the terminology "noise representation."
} 
to news as follows:

$$
\theta_{t+h}-E_{t-1} \theta_{t+h}=\sum_{j=0}^{h} \varepsilon_{R, t+h-j}^{j}
$$

This equation states that the error in the forecast of $\theta_{t+h}$ made in date $t-1$ equals the sum of all news about it revealed from date $t$ to date $t+h$. The variance-covariance matrix of the $H+1$ random variables $\theta_{t+h}-E_{t-1} \theta_{t+h}$ corresponds to $\Xi_{\theta}$. Therefore given a stochastic process for news we can calculate the variance-covariance matrix of the random variables $\sum_{j=0}^{h} \varepsilon_{R, t+h-j}^{j}$ and thereby obtain $\Xi_{\theta}$ using the relationship between news and the forecast errors of policy deviations given by (8).

Using (7) the variance-covariance matrices of the communications technology are related to the variance-covariance matrix of the vector of news, $\Sigma_{\varepsilon} \equiv E\left(\varepsilon_{R, t} \varepsilon_{R, t}^{\prime}\right)$, according to

$$
\Xi_{\theta}\left[\Xi_{\theta}+\Xi_{v}\right]^{-1} \Xi_{\theta}=\Sigma_{\varepsilon}
$$

With $\Xi_{\theta}$ in hand we can use this equation to solve for the variance-covariance matrix of noise:

$$
\Xi_{v}=\left[\Xi_{\theta}^{-1} \Sigma_{\varepsilon} \Xi_{\theta}^{-1}\right]^{-1}-\Xi_{\theta}
$$

The foregoing demonstrates that if we have the stochastic process of news in hand we can obtain the parameters of the communications technology. We obtain the stochastic process for news by estimating the news representation of the model. In the news representation we suppose that instead of communicating noisy signals about future policy deviations the central bank communicates news. Specifically, each period $t$ the central bank perfectly communicates the $(H+1) \times 1$ vector $\varepsilon_{R, t}$. At the time this information is communicated agents believe it represents credible commitments to deviate from the rule up to $H$ periods in the future with the full knowledge that more news may come along that changes expectations about future deviations. Any given period's policy deviation is communicated through news for up to $H$ periods before the policy deviation is realized. It follows that the policy deviation at date $t, \theta_{t}$, is related to news according to

$$
\theta_{t}=\sum_{j=0}^{H} \varepsilon_{R, t-j}^{j}
$$


The news representation is obtained simply by replacing $\theta_{t}$ in equation (1) with $\sum_{j=0}^{H} \varepsilon_{R, t-j}^{j}$.

To complete the description of the news representation we need to specify the stochastic process for news. For this we adopt the factor structure used in Campbell et al. (2017) and described in the appendix. This factor structure allows for the possibility of serially correlated policy deviations and so is consistent with the signal representation. With this specification the model we estimate is essentially identical to the model estimated in Campbell et al. $(2017) .^{8}$

\subsection{Estimating the news representation}

Our estimation of the model's news representation proceeds in two steps. The first step is to calibrate the parameters that appear in the corresponding neoclassical growth model to match sample averages from the U.S. economy. With the exceptions noted below to address low frequency movements in growth and interest rates these parameters are held fixed throughout the analysis. The second step takes the calibrated parameters as given and applies standard Bayesian methods to estimate the remainder of the model plus some auxiliary parameters which are used to map the model into the data.

Our calibration strategy is the same as in Campbell et al. (2017) except that we address the well-known evidence of secular declines in economic growth and rates of return on nominally risk free assets. We address these developments by imposing a change in steady state in 2008q4 (the choice of this date is motivated below.) Steady state GDP growth is governed by the mean growth rates of the neutral and investment-specific technologies, $\nu_{*}$ and $\omega_{*}$. We adjust $\omega_{*}$ down to account for the slower decline in the relative price of investment since 2008q4. Given this change we then lower $\nu_{*}$ so that steady state GDP growth is reduced to $2 \%$. To match a lower real risk-free rate of $1 \%$ we increase the steady state marginal utility of government bonds using $\varepsilon_{*}^{s .9}$ These adjustments leave the other calibrated parameters unchanged but do change the steady state values of the endogenous variables and therefore the point at which the economy is log-linearized. ${ }^{10}$

\footnotetext{
${ }^{8}$ In the appendix we explain in detail how to obtain estimates of $\Xi_{\theta}$ and $\Xi_{\nu}$ as well as the time series of noise, $v_{t}$, from the estimated model. We can use (10) to obtain the time series for $\boldsymbol{\theta}_{t}$.

${ }^{9}$ The targets for steady state GDP growth and risk-free rate reflect a variety of evidence including the Fed's Summary of Economic Projections.

${ }^{10}$ Our re-calibration changes the return on private assets by a little. This small change is consistent with
} 
Our Bayesian estimation uses the same split-sample strategy as in Campbell et al. (2017) except that we incorporate the change in steady state described above and one other change noted below. As in Campbell et al. (2017) our sample begins in 1993q1. This date is based on the availability and reliability of the overnight interest rate futures data. The sample period ends in 2016q4 but we impose a sample break in 2008q4. Our choice of this latter date is motivated by three main considerations. First, there is the evidence that points to lower interest rates and economic growth later in the sample. Second, it seems clear that the horizon over which forward guidance was communicated by the Fed lengthened substantially during the ELB period. Finally, the downward trends in inflation and inflation expectations from the early 1990s appear to come to an end in the mid-2000s. Splitting the sample in $2008 \mathrm{q} 4$ and assuming some parameters change at that date is our way of striking a balance between parsimony and addressing the multiple structural changes that seem to occur around the same time.

We estimate the full suite of non-calibrated structural parameters in the first sample under the assumption that forward guidance extends for $H=4$ quarters. Starting in $2008 \mathrm{q} 4$ we assume the model environment changes in three ways. First we assume the change in the steady state described above. Second, forward guidance lengthens to $H=10$ quarters. Third, the time-varying inflation target from the first sample becomes a constant equal to the steady state rate of inflation, $2 \%$ at an annual rate. All three changes are assumed to be unanticipated and permanent.

The measurement equations for the first sample estimation are as follows:

$$
\begin{aligned}
\Delta \ln Q_{t}^{o b s} & =f\left(\hat{c}_{t}, \hat{c}_{t-1}, \hat{i}_{t}, \hat{i}_{t-1}, \hat{g}_{t}, \hat{\omega}_{t}, \hat{\pi}_{t}^{g, o b s}\right) \\
\Delta \ln C_{t}^{o b s} & =z_{*}+\Delta \hat{c}_{t}+\hat{z}_{t} ; \\
\Delta \ln I_{t}^{o b s} & =z_{*}+\omega_{*}+\Delta \hat{\imath}_{t}+\hat{z}_{t}+\hat{\omega}_{t} ; \\
\log H_{t}^{o b s} & =\hat{H}_{t} ; \\
\pi_{t}^{i, o b s} & =\omega_{*}+\hat{\omega}_{t}+u_{t}^{i} ; \\
R_{t}^{o b s} & =R_{*}+\hat{R}_{t}
\end{aligned}
$$

Yi and Zhang (2017) who show that rates of return on private capital have stayed roughly constant in the face of declines in risk free rates. 


$$
\begin{aligned}
R_{t}^{j, o b s} & =R_{*}+E_{t} \hat{R}_{t+j}, j=1,2, \ldots, H \\
\pi_{t}^{l, j, o b s} & =\pi_{*}+\pi_{*}^{l, j}+\frac{\beta^{l, j}}{l} \sum_{i=1}^{l} E_{t} \hat{\pi}_{t+i}+u_{t}^{l, j, \pi}, j=1,2, \quad l=1,40 ; \\
\pi_{t}^{j, o b s} & =\pi_{*}+\pi_{*}^{j}+\beta^{\pi, j} \hat{\pi}_{t}+\gamma^{\pi, j} \pi_{t}^{d, o b s}+u_{t}^{j, p}, \quad \text { with } \beta^{\pi, 1}=1, j=1,2,3 ; \\
\Delta \ln w_{t}^{j, o b s} & =z_{*}+w_{*}^{j}+\beta^{w, j}\left(\hat{w}_{t}-\hat{w}_{t-1}+\hat{z}_{t}\right)+u_{t}^{j, w}, \text { with } \beta^{w, 1}=1, j=1,2 ; \\
\pi_{t}^{d, o b s} & =\pi_{*}^{d}+\beta_{1,1} \pi_{t-1}^{d, o b s}+\beta_{1,2} \pi_{t-2}^{d, o b s}+u_{t}^{d} ; \\
\pi_{t}^{g, o b s} & =\pi_{*}^{g}+\beta_{2,1} \pi_{t-1}^{g, o b s}+\beta_{2,2} \pi_{t-2}^{g, o b s}+u_{t}^{g} .
\end{aligned}
$$

The "hat" notation denotes log deviations from steady state; the de-trended counterparts of the upper case endogenous variables described in Section 3 are denoted with their corresponding lower case; and " $\Delta$ " is the first difference operator. The left hand side variables represent data $(Q$ denotes chain-weighted GDP). These data are described in Campbell et al. (2017). ${ }^{11}$ The function $f$ in the first equation represents the linear approximation to the chain-weighted GDP formula discussed in Campbell et al. (2017). Two variables are included to complete the mapping from model to data but are not endogenous to the model. Specifically, the consumption price of government consumption plus net exports, $\pi_{t}^{g, o b s}$, helps map model GDP to our model-consistent measure of chain-weighted GDP, and inflation in the consumption price of consumer durable goods, $\pi_{t}^{d, o b s}$, is used to complete the mapping from model inflation to measured inflation. ${ }^{12}$

These equations indicate we use 21 time series to estimate the model in the first sample. In addition to the real quantities and federal funds rate that are standard in the literature our estimation includes multiple measures of wage and consumer price inflation, two measures each of average inflation expected over the next ten years and over one quarter, and $H=4$ quarters of interest rate futures. Our second sample estimation is restricted to estimating

\footnotetext{
${ }^{11}$ We use three additional time series, all measures of expected inflation from the Survey of Professional Forecasters: PCE expected inflation over the next 10 years and both CPI and PCE expected inflation one quarter out.

${ }^{12}$ The measurement equations introduce some additional notation: $\pi_{t}^{j, o b s}$ and $w_{t}^{j, o b s}$ represent the inflation and wage indicators discussed in Campbell et al. (2017); $\pi_{t}^{l, j, o b s}$ denote measures of inflation expectations; $u_{t}^{i}$, $u_{t}^{l, j, \pi}, u_{t}^{j, p}$ and $u_{t}^{j, w}$ denote classical measurement errors; $u_{t}^{d}$ and $u_{t}^{g}$ denote regression residuals; $\pi_{*}^{j}$ and $\pi_{*}^{l, j}$ are constants that account for the average differences between the observable measures of inflation and inflation expectations and steady state inflation; $\beta^{\pi, j}$ and $\gamma^{\pi, j}$ denote the factor loadings relating observable inflation to model inflation and observed consumer durable inflation; $\beta^{l, j}$ are factor loadings relating observable inflation expectations to their model counterparts; and $\beta_{i, j}$ denote regression coefficients.
} 
the parameters of the stochastic process for forward guidance news with $H=10$ plus the

processes driving $\pi_{t}^{g, o b s}$ and $\pi_{t}^{d, o b s}$. This estimation uses the measurement equations involving the current federal funds rate and 10 quarters of expected future policy rates plus the last two equations. We take into account the change in steady state but keep the remaining structural parameters at their first sample values. Because our estimation forces data on real activity, wages and prices to coexist with the interest rate futures data, we expect the estimation to mitigate the forward guidance puzzle. Finally, it is worth reiterating that our estimation respects the ELB in the second sample. This is because we measure expected future rates in the model, the $E_{t} \hat{R}_{t+j}$, using the corresponding empirical futures rates, $R_{t}^{j, o b s}$, and we use futures rates extending out 10 quarters.

\subsection{The estimated model}

The differences in the estimation strategy compared to Campbell et al. (2017) do not change the desirable properties of the estimated model. The vast majority of business cycle variation in real variables is driven by five shocks: neutral and investment-specific technology, liquidity preference, discount factor, and investment demand. Markup shocks contribute very little to real fluctuations and in the first sample monetary policy shocks contribute little as well. The model also continues to provide a plausible interpretation of the two recessions in our sample. The 2001 recession is explained by tighter financial conditions, i.e. an increase in demand for government bonds, and to a lesser extent weaker technology growth. During this recession the sharp drop in the funds rate is larger than stipulated by the policy rule and this lifts aggregate activity and inflation. Tighter financial conditions are the main driver of the Great Recession and the constraint of the ELB led to monetary policy being a substantial drag on real activity. Finally, the estimated model does not exhibit an empirical forward guidance puzzle. In particular, when we conduct the experiment in Del Negro et al. (2015) in which the low interest rate peg anticipated by markets in 2012q3 is extended by one quarter we find small effects on real activity and inflation. 


\section{The information flows from Fed communications}

This section quantifies the information content of the policy signals we isolate using the estimated model. We do this in two ways. First, we measure the reduction in the uncertainty about the future path of the policy rate due to the individual entries of the signal vector. Second, we study the rate at which agents' uncertainty falls as the time of a policy implementation approaches. These exercises offer evidence on the limits of forward guidance if the central bank tries to steer private sector expectations over many periods.

\subsection{Information about the policy path embedded in $s_{t}$}

We measure the information about the policy path embedded in $s_{t}$ starting from a situation in which agents have received signals up to $t-1$ and do not have any time $t$ signals. We then suppose that at time $t$ the central bank sends signals within the vector $s_{t}$ sequentially starting with the longest horizon $H$. For each new signal we measure the reduction in uncertainty relative to not having received any time $t$ signals. This allows us to quantity the role of the individual signals in reducing agents' uncertainty about the monetary policy path.

In the signal representation, agents' uncertainty about future policy is encoded in its unconditional and conditional variance-covariance matrices. The concept of entropy, defined as the average uncertainty of random vectors, allows us to summarize this uncertainty with a scalar while preserving the estimated correlation structure of the signals. For a Gaussian distributed random vector, $x \sim N(\mu, \Sigma)$, the entropy is given by

$$
\xi(x)=\frac{1}{2} \log _{2}|\Sigma|+\frac{n}{2}\left(\log _{2} 2 \pi e\right),
$$

where $n$ is the dimension of $x$. We quantify the role of individual signals in reducing agents' uncertainty about the monetary policy path using the reduction in entropy due to the signals. $^{13}$

We focus on the future path of monetary policy, $\boldsymbol{\theta}_{t}^{p}$, the $H \times 1$ vector of future policy deviations that excludes the perfectly revealing contemporaneous signal $s_{t}^{0}=\theta_{t}$. The

\footnotetext{
${ }^{13}$ Reduction in entropy is a widely used metric in the engineering literature to measure information flows, e.g. Cover and Thomas (1991). In economics, the rational inattention literature uses this measure to characterize the information-processing constraint, e.g. Sims (2003) and Maćkowiak and Wiederholt (2009).
} 
information gains, or reduction in uncertainty, induced by the revelation of signals can be measured by taking the difference between the posterior entropy of receiving the signals of policy deviations $H$ to $H-h$ quarters out, $h=0,1, \ldots, H-1$, minus the prior entropy of not receiving any new signals at all. Usually, entropy is measured in 'bits'. We express the information gains as fractions. Specifically, we define the information gains of receiving the $h+1$ signals for horizons $H-h$ to $H$ as

$$
\begin{aligned}
\mathcal{G}(h) & =1-\exp \left[\xi\left(\boldsymbol{\theta}_{t}^{p} \mid s^{t-1}, s_{t}^{H}, s_{t}^{H-1}, \ldots, s_{t}^{H-h}\right)-\xi\left(\boldsymbol{\theta}_{t}^{p} \mid s^{t-1}\right)\right] \\
& =1-\exp \left[\frac{1}{2} \log _{2}\left|\Xi_{\theta, h}^{p}\right|-\frac{1}{2} \log _{2}\left|\Xi_{\theta}^{p}\right|\right] .
\end{aligned}
$$

Here $s^{t-1}$ denotes the history of all signals received up to and including period $t-1 ; \Xi_{\theta}^{p}$ and $\Xi_{\theta, h}^{p}$ correspond to the variance-covariance matrices of the posterior and prior distributions of $\boldsymbol{\theta}_{t}$, respectively, and are derived in the appendix.

The information gains $\mathcal{G}(h)$ induced by signals $H-h$ to $H$ indicate the fraction of the reduction in the entropy of the monetary policy path $\boldsymbol{\theta}_{t}^{p}$ that is attributable to these signals alone. When the difference between the posterior and prior entropy, the argument in the exponential, is close to zero, the reduction in uncertainty is small and hence so are the information gains. Conversely, when the reduction in the posterior entropy is sizable, the argument in the exponential is negative and information gains become large. If all uncertainty is resolved after receiving $h+1$ signals then $\mathcal{G}(h)=1$.

Figure 1 reports the information gains in the first and second samples. The information gains show the accumulated reduction in uncertainty in the policy path as the central bank progressively reveals signals about its individual components. We start from the horizon furthest out and progressively add signals at shorter horizons. In the first sample agents receive the first signal four quarters before its corresponding policy deviation is actually implementated, whereas in the second sample signals about future deviations are emitted as early as ten quarters in advance.

The first sample plot shows close to zero reduction in uncertainty four quarters out. This means that uncertainty about the monetary policy path when the central bank announces only the deviation from the rule one year out hardly changes the agents' uncertainty about 
Figure 1: Cumulative information gains

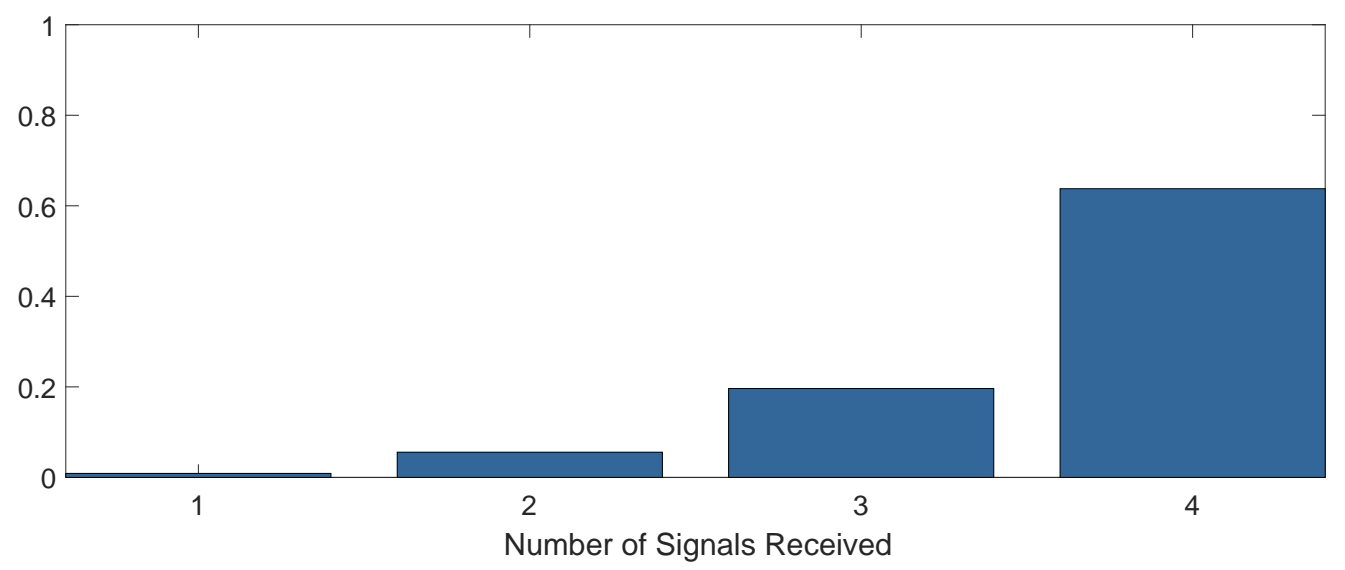

(a) First Sample

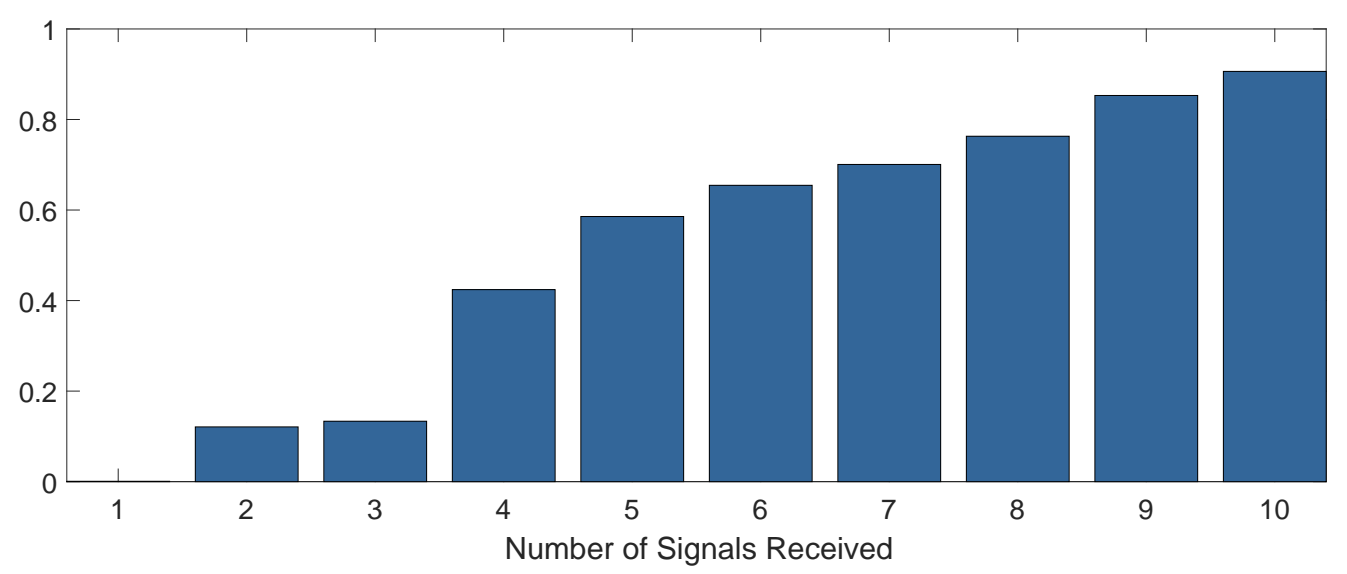

(b) Second Sample

Note: Each bar represents $\mathcal{G}(h)$ where the $x$-axis indicates the number of signals, $h+1$, received and $h=0,1, \ldots, H-1$.

future policy deviations. Agents barely update their beliefs. The reduction in uncertainty is just $20 \%$ when agents have received three signals already. It is only when they receive the signal about the next quarter policy rate that we see a substantial reduction in uncertainty but even then it is only about $60 \%$. So in normal times it appears the Fed has a very limited ability to use forward guidance to influence private sector expectations.

The second sample plot shows virtually zero reduction in uncertainty 10 quarters out. There is a discrete jump 7 quarters out and another 6 quarters out that lifts the information gain above $50 \%$. By 2 quarters out about $80 \%$ of uncertainty is reduced. These results cast 
doubt on the power of forward guidance to affect agents' uncertainty about future deviations at horizons very far from the policy implementation. However the larger information gains at longer horizons in the second sample compared to the first sample suggest that the tool of forward guidance may have some bite during periods of extreme economic distress. Nevertheless there are limits to the power of this tool even then. It seems very difficult to convince the public that an interest rate peg can be extended for very long. From this perspective there is no forward guidance puzzle. In particular, Del Negro et al. (2015) frame the forward guidance puzzle as implausibly large effects on aggregate activity from extending the 10 quarter low interest rate peg expected by markets in $2012 \mathrm{q} 3$ to 11 quarters. Figure 1 suggests it was not possible for the Fed to communicate such an extension.

We conjecture that the relatively large information gains at longer horizons in the second sample arise from two factors. First, it is possible that the extreme economic conditions during the second sample may have led agents to pay more attention to the Fed than they did during more normal times. This should be reflected in the Kalman gain matrix. ${ }^{14}$ Second, it may be easier to communicate when policy is constrained by the ELB. Communicating policy deviations while being constrained by the ELB boils down to explaining how long the policy rate will remain near zero which seems relatively easy to do. ${ }^{15}$

\subsection{Accumulation of knowledge about a future policy deviation}

We now examine the rate at which agents' uncertainty about the deviation from the monetary policy rule at a fixed date in the future resolves over time. We call this the accumulation of knowledge about a future policy deviation. We quantify the accumulation of knowledge by looking at the reduction in entropy of the deviation from the policy rule as we approach the policy implementation. Specifically, the reduction in entropy after receiving $h+1$ vectors of

\footnotetext{
${ }^{14}$ We have not framed our analysis in terms of the optimal allocation of attention. However there is a close connection between the Kalman gain and this allocation problem. See for example Maćkowiak and Wiederholt (2009) and Melosi (2014).

${ }^{15}$ Our analysis abstracts from the Fed's large scale asset purchases. To the extent that the macroeconomic effects of these policies were through signalling or establishing a commitment to keep rates lower for longer they can be viewed through the lens of forward guidance communications we consider in this paper.
} 
signals that include information about the policy deviation at $t+H$ is given by

$$
\mathcal{K}(h)=1-\exp \left[\xi\left(\theta_{t+H} \mid s^{t+h}\right)-\xi\left(\theta_{t+H} \mid s^{t-1}\right)\right], \quad h=0,1,2, \ldots, H
$$

Here $\xi\left(\theta_{t+H} \mid s^{t-1}\right)$ is the prior entropy of $\theta_{t+H}$, which measures agents' uncertainty about $\theta_{t+H}$ before having received any signals about it, and $\xi\left(\theta_{t+H} \mid s^{t+h}\right)$ is the posterior entropy conditional on receiving $h+1$ vectors of signals. ${ }^{16}$ Since the last signal is perfectly revealing $\mathcal{K}(H)=1$.

Figure 2 reports the accumulation of knowledge, $\mathcal{K}(h)$, in the first and second samples. The $x$-axis in the plots indicates the quarters before the policy deviation is implemented. For example the left-most bars correspond to the case $h=0$ in which only one vector of signals about the policy deviation at $t+4$ has been communicated. Knowledge accumulates at a fairly steady pace both in the first and second sample. In the first sample the reduction in uncertainty is sizable only one period away from the policy implementation, while in the second sample the size of uncertainty is reduced by half more than a year before the policy is implemented. Figure 2 reinforces the main lessons from Figure 1. In the first sample it was hard to communicate much more than 1 quarter before a policy decision. In the second sample the communication horizon was substantially longer, but limited.

\section{The dynamic effects of a forward guidance shock}

Now we explore the role of communication in the dynamic response of the economy to a hypothetical forward guidance shock. We define a forward guidance shock as an orthogonalized shock to $\boldsymbol{s}_{t}$ that implies a zero signal about the current deviation and non-zero signals about all future deviations up to $H$ periods ahead. The forward guidance shock is constructed by first decomposing the signal equation (2) as follows:

$$
s_{t}=\boldsymbol{\theta}_{t}+v_{t}=\Phi u_{t}
$$

\footnotetext{
${ }^{16}$ The variance used in the posterior entropy $\xi\left(\theta_{t+H} \mid s^{t+h}\right)$ corresponds to the $(H+1-h) \times(H+1-h)$ element of the variance-covariance matrix of the posterior distribution of the entire state $\boldsymbol{\theta}_{t} \mid s^{t+h}$ which is described in the appendix.
} 
Figure 2: Dynamic accumulation of knowledge

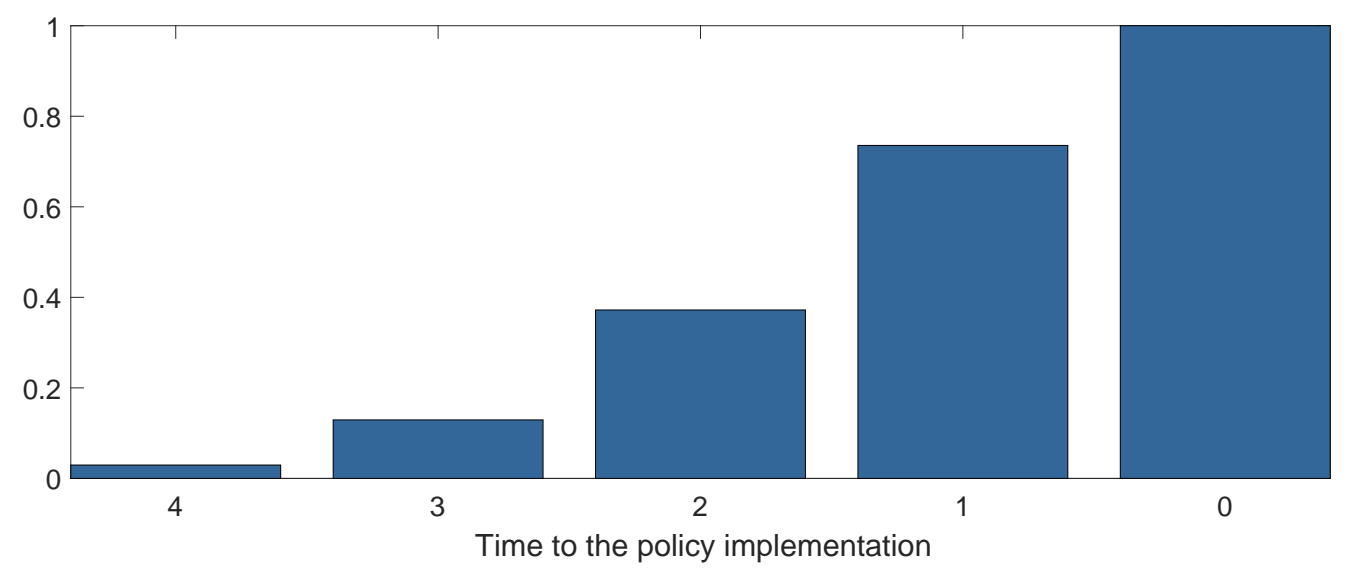

(a) First Sample

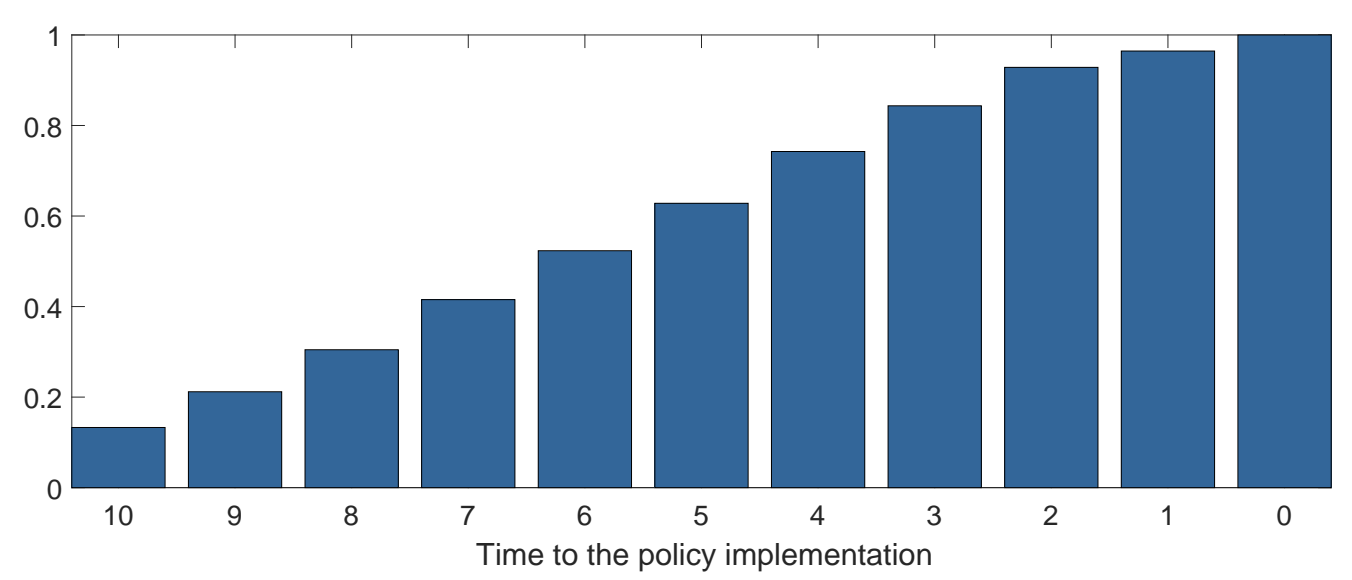

(b) Second Sample

Note: Each bar represents $\mathcal{K}(h)$ where the $x$-axis indicates the time to the implementation of the deviation from the policy rule, $H-h, h=0,1, \ldots, H$.

where $u_{t} \sim \mathcal{N}(\mathbf{0}, \mathbf{I})$ is a $(H+1) \times 1$ random vector of shocks and the matrix $\Phi$ is lower triangular with $E\left(\Phi u_{t} u_{t}^{\prime} \Phi^{\prime}\right)=E_{t-1}\left(s_{t} s_{t}^{\prime}\right)=\Xi_{\theta}+\Xi_{\nu}$. A forward guidance shock corresponds to a unit innovation to the second element of the vector $u_{t}$ fixing all other elements equal to zero. This represents a forward guidance shock since it consists of an orthogonalized vector of signals that implies no deviation from the policy rule contemporaneously but a change in the path going forward. ${ }^{17}$

\footnotetext{
${ }^{17}$ Other shocks are potentially interesting to study. The $h^{\text {th }}$ shock in $u_{t}$ is the shock that does not affect signals concerning deviations that will occur from period $t$ through period $t+h-1$. While these shocks certainly belong to the forward guidance class, they do not affect all the signals concerning future deviations from the rule. Therefore, the second shock seems like the most natural candidate to study.
} 
This section uses the dynamic response of the model economy to a forward guidance shock so constructed to make three main points. First, imperfect communication delays and later amplifies the response of the economy to forward guidance compared to perfect communication. Second, even with imperfect communication there is a substantial role for expectations in the transmission of forward guidance to shift its effects earlier than they would be compared to no communications. Finally, miscommunication in the form of noise is a source of substantial macroeconomic volatility.

\subsection{The role of imperfect communication}

To study the role of imperfect communications in propagating a forward guidance shock we consider the following scenario. The central bank announces a vector of signals in an arbitrary period $t$ that contains no noise and comprises its actual policy deviations from period $t+1$ through period $t+H$. The announcement comes when the economy is initially at steady state and so before it is made agents expect that all future deviations are zero. However, to be consistent with our learning environment, we also assume that before the announcement agents have received $H-h$ signals equal to zero about the $h$ th quarter ahead deviation from the rule, and this information is embedded in their prior uncertainty. Further, we assume that over the period $t+1$ to $t+H$ the central bank continues to send accurate signals about its policy deviations but does not send signals beyond the horizon of the initial forward guidance. Since the signals are the only source of information for the private sector to learn about future policy deviations, agents' expectations about the deviations from time $t+H$ onward equal zero, which is the unconditional mean of the policy deviations. No more deviations will be carried out after period $t+H$. These two assumptions imply that agents correctly anticipate the model economy is not hit by any shock after period $t+H$ and will transition back to the steady state.

Given this setup we consider two ways in which the forward guidance shock is communicated to private agents. In the perfect communication case we assume agents learn with the Kalman gain matrix $\kappa$ set equal to the identity matrix. In the imperfect communication case agents learn with our estimated Kalman gain matrix. These two cases allow us to measure how imperfect communication influences the response to forward guidance. 
Figure 3: Expectations about future policy deviations after a forward guidance shock in the second sample
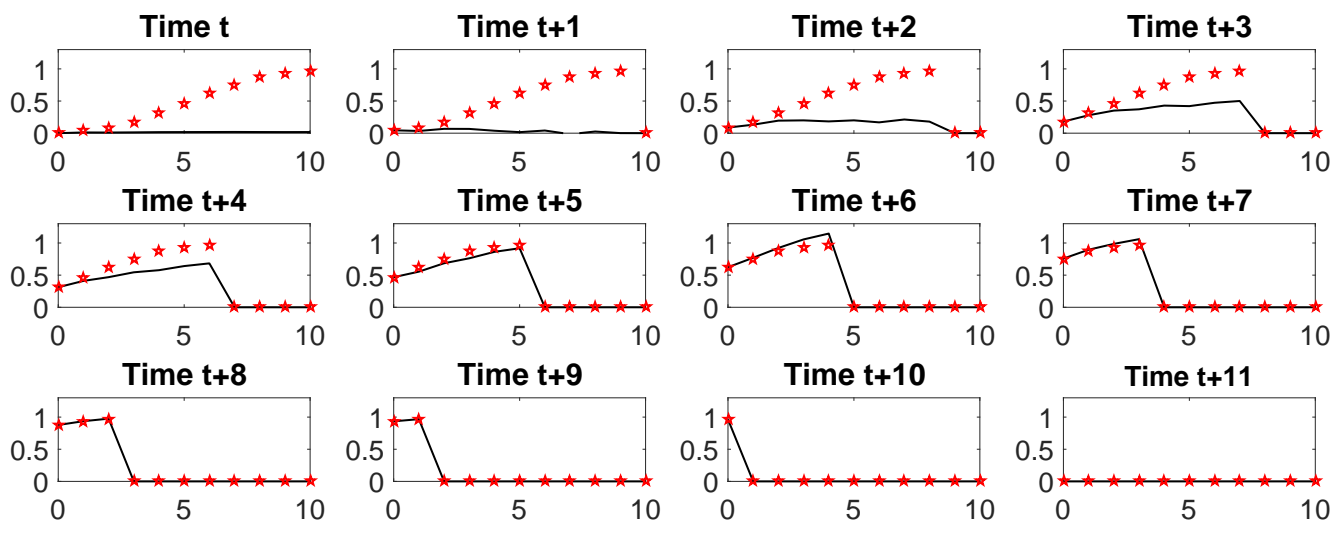

Note: Response of private sector's expectations about future deviations from the policy rule to a forward guidance shock. The black solid line denotes the case of imperfect communication and the red stars mark the case of perfect communication. The units are percentage points at annualized rates.

Figure 3 shows the influence of imperfect communication on agents' expectations about future policy deviations in the most recent sample. We normalize the forward guidance shock so that it leads the annualized interest rate to deviate from its rule-consistent value by 100 basis points after 10 quarters. ${ }^{18}$ The red stars indicate the actual future deviations from the rule looking ahead from each date following the forward guidance shock. They also correspond to the signals sent by the central bank because we have assumed these signals do not contain any noise. Recall that the signals perfectly reveal the current deviation and hence the stars associated with horizon 0 on the $x$-axis of each plot correspond to the actual deviation in the indicated period following the shock. The black lines show the private sector's expectations about future policy deviations with imperfect communications. The expectations are over the next 10 quarters, $E_{t} \boldsymbol{\theta}_{t}$, at time $t$, which is when the first announcement is made, and in the following periods. With perfect communications the analogous expectations are just the red stars.

Figure 3 shows that at time $t$, the central bank spectacularly fails to communicate its future deviations from the rule. Expectations about future deviations hardly budge. The second announcement at time $t+1$ does not seem to materially move agents' expectations either. At time $t+2$, the third announcement has some impact and lifts private expectations

\footnotetext{
${ }^{18}$ This requires us to re-scale the forward guidance shock by 4 .
} 
Figure 4: Response of hours to a forward guidance shock in the second sample

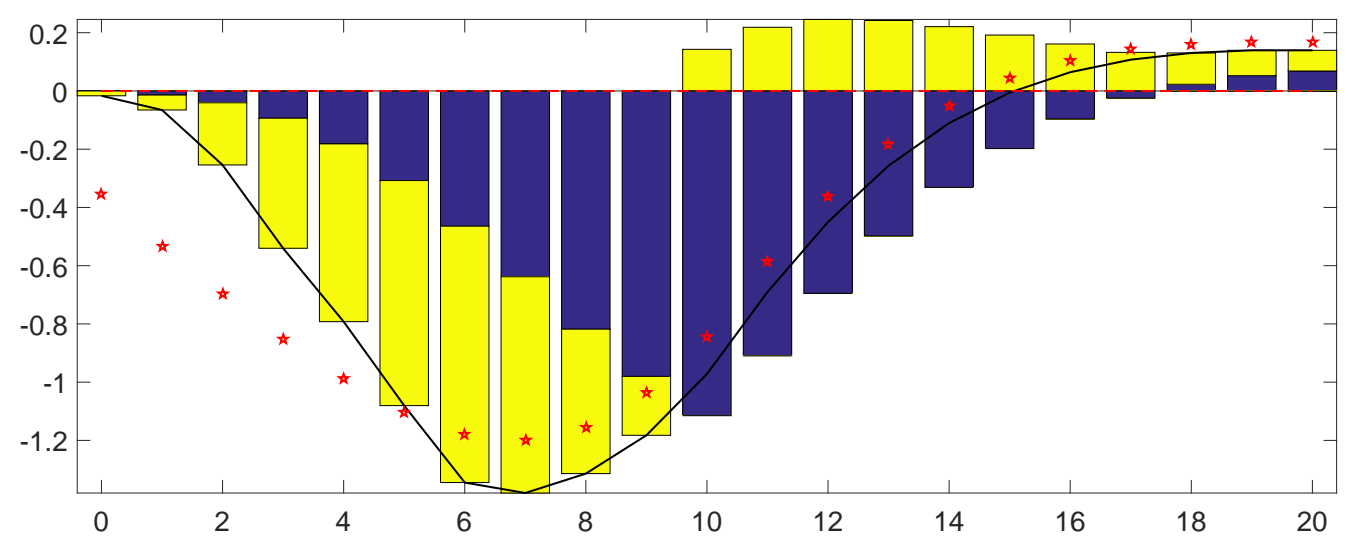

Note: Response of hours to a forward guidance shock that causes the interest rate to deviate from its rule-consistent value by 100 basis points in 10 quarters. The black solid line denotes the case of imperfect communication, the red stars mark the case of perfect communication, the yellow bars indicate the effect on the imperfect communication response due to expectations about future policy deviations alone, and the blue bars show the response when the future policy deviations are not communicated and only implemented as surprises. The units are percentage point deviations from steady state.

toward the truth (the red stars) a bit. From period $t+3$ on, agents' expectations quickly rise, overshoot the true deviations in periods $t+6$ and $t+7$, and finally line up with the truth in period $t+8$ and in subsequent periods. These patterns seem very much in line with the cumulative information gains shown in Figure 1 and suggests that it takes four or five periods of forward guidance for agents to have gathered enough information to start adjusting their expectations in line with what the future deviations will actually be.

The findings in the top row of Figure 3 are striking and call for caution in using the news representation of a model to study the macroeconomic effects of forward guidance. In the news representation future deviations are perfectly communicated. This plot shows that the central bank's ability to steer expectations about future monetary policy is substantially limited. Therefore, using the news representation is likely to lead to inaccurate predictions or to puzzles (e.g., the forward guidance puzzle) that would not arise if one takes into account the imperfect ability of the central bank to communicate. But to do this, one needs to consider the signal representation.

Figure 4 shows the response of hours to the forward guidance shock in the most recent sample. ${ }^{19}$ We discuss the yellow and blue bars in this figure below and focus here on the

\footnotetext{
${ }^{19}$ We use the news representation to obtain these impulse response functions. The case of perfect commu-
} 
black line and red stars. The black line and red stars correspond to the imperfect and perfect communication cases, respectively. Hence, the difference between them captures the effects of the central bank not being able to perfectly communicate the future course of policy. Imperfect communication delays the response of real activity to forward guidance and amplifies it in the medium term. At the time of the first forward guidance (time $t$ ), hours barely adjust because private sector expectations fail to react to the announcement, as shown in Figure 3. As time goes by and more and more guidance is provided, private sector expectations adjust and consequently economic activity quickly deteriorates and contracts more than in the case of perfect information.

There are two reasons why imperfect communication triggers a deeper recession compared to perfect communication. First, as shown in Figure 3, the overshooting of expectations about the path of contractionary monetary shocks in period $t+6$ and $t+7$ contributes to deepen the recession. Second, the delayed revisions of agents' expectations contribute to lower hours. In the perfect communication case, agents never revise their expectations about future deviations after the first announcement is made. Under imperfect communications agents largely fail to anticipate the path of policy initially and then revise their expectations slowly over time. Consequently, when agents finally learn the future policy deviations, they have less time to adjust to the consequences of them relative to the case of perfect communication. As in all standard NK models a shorter anticipation time for future deviations boosts the response of real activity. When firms anticipate a monetary shock long in advance, the effects will be relatively small because less firms are constrained by the Calvo lottery before the anticipated policy deviation is realized. ${ }^{20}$ More flexible prices imply a smaller response of real activity. Thus, by slowing down the information flow from the central bank to the private sector, imperfect communication magnifies the effects of forward guidance on real activity.

Figure 5 shows the expected deviations from the rule following a forward guidance shock

nication is constructed by imposing that the news shocks in the first period are equal to the actual future deviations and zero in the following periods. The case of imperfect information is constructed by premultiplying the actual future deviations by the estimated Kalman gain matrix and then by using the resulting revision of expectations about future deviations as news shocks to simulate the news representation.

${ }^{20}$ This result also holds in presence of Rotemberg-style price adjustment. A long anticipation horizon allows firms to smooth out the price changes over a longer period and hence lowers the cost for firms to change their price relative to a surprise monetary shock. 
Figure 5: Expectations about future policy deviations after a forward guidance shock in the first sample
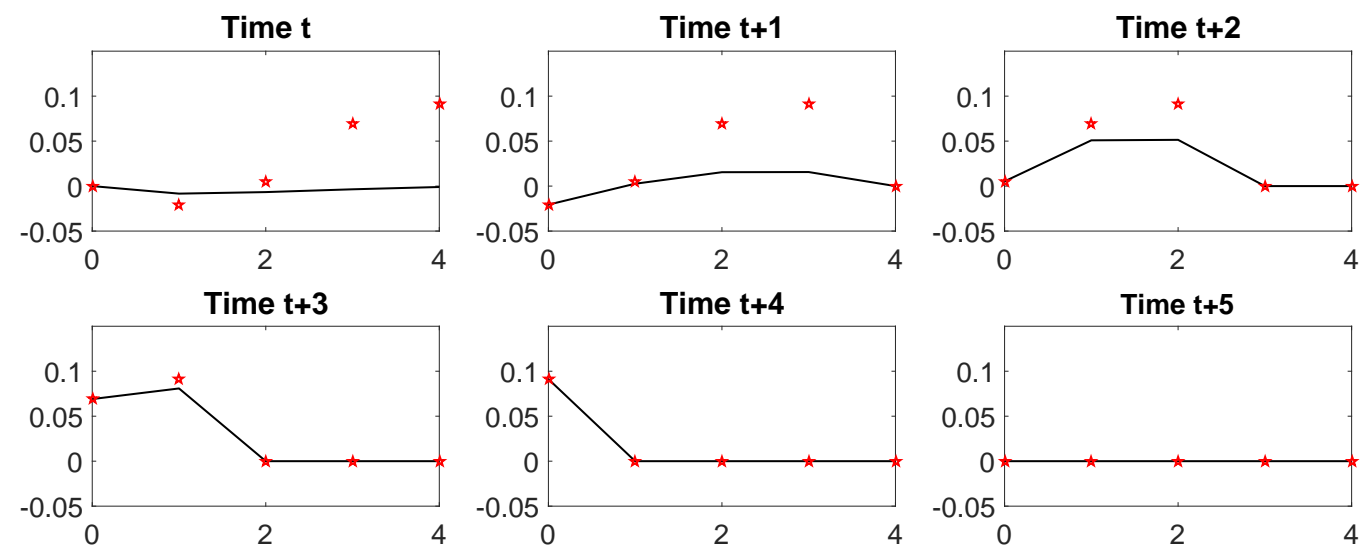

Note: Response of private sector's expectations about future deviations from the policy rule to a forward guidance shock. The black solid line denotes the case of imperfect communication and the red stars mark the case of perfect communication. The units are percentage points of annualized rates.

in the first sample. The figure is constructed analogously to Figure 5 and the scales are comparable so we see that forward guidance shocks in the first sample are only $8 \%$ as volatile as in the second sample. ${ }^{21}$ Recall that forward guidance in the first sample extends out only $H=4$ quarters. Figure 5 indicates the central bank poorly communicates its future policy deviations in the first three periods. This is reflected in the black lines being far from the red stars in period $t$, when the first announcement is made, and in the following two periods. Consistent with the accumulation of knowledge shown in Figure 2, only when the central bank has made four announcements do private sector expectations become very close to the actual deviations.

The responses of hours to a forward guidance shock in the first sample under perfect and imperfect communication are shown in Figure 6. These are qualitatively similar to those in the second sample. Imperfect communication initially delays and later amplifies the response of hours. Compared to the second sample the effects are smaller due to the small size of the shock, and are less persistent due to the shorter duration of the guidance.

While we have assumed that forward guidance is exogenous and risk has no impact on

\footnotetext{
${ }^{21}$ The extremely small shocks in the first sample indicate two important features of our estimation. First, the small size of the deviations indicate the estimated policy rule is an excellent summary of the Fed's behavior. Second, the Fed did not do much forward guidance in the first sample. These features are likely influenced by our assumption that the inflation drift shock is perfectly communicated.
} 
Figure 6: Response of hours to a forward guidance shock in the first sample

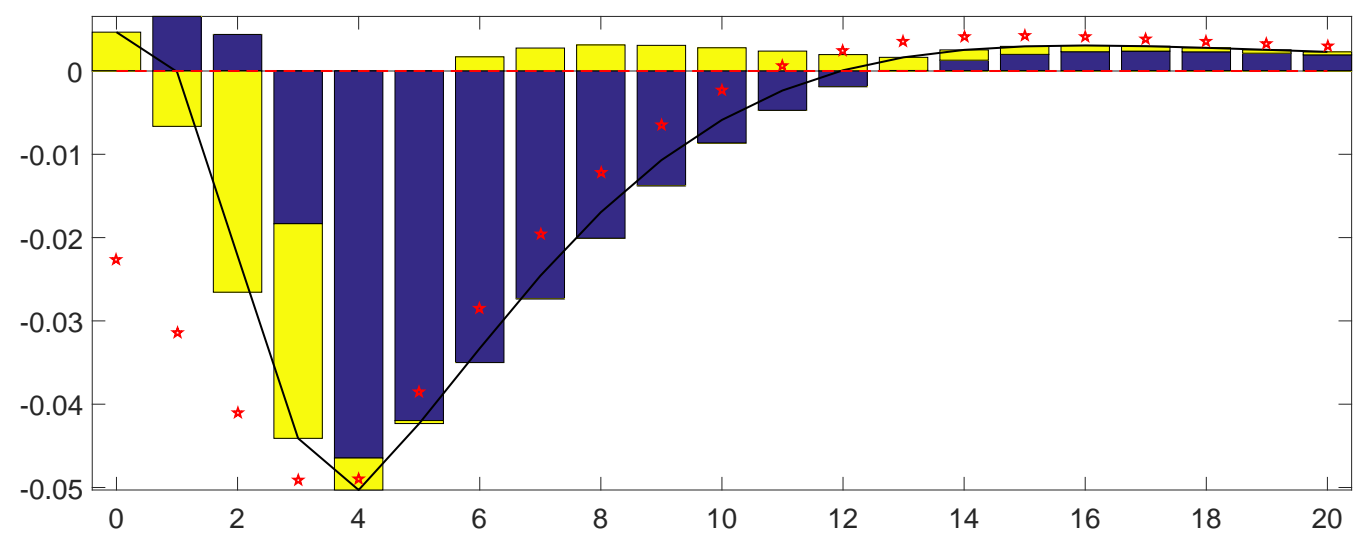

Note: Response of hours to a forward guidance shock that causes the interest rate to deviate from its rule-consistent value by 8 basis points in 10 quarters. The black solid line denotes the case of imperfect communication, the red stars mark the case of perfect communication, and the blue circles refer to the case where the forward guidance shock does not lead to any actual deviations from the rule (pure beliefs). The units are percentage deviations from steady state.

agents' decisions in our linearized model, we think the dynamic responses of hours shown in Figures 4 and 6 are informative about the use of forward guidance as a risk management tool, for the reasons discussed in Section 2. The delayed response of the economy with our estimated communications technologies suggests that imperfect communication hampers the use forward guidance as a risk management tool. If a central bank wants to use forward guidance as a risk management tool its effects may come too late to have the desired impact on the economy. Nevertheless the extent of the communication imperfections that we estimate do not render forward guidance completely impotent, which we now demonstrate.

\subsection{The expectations channel of forward guidance}

We show in the appendix that the signal representation allows us to decompose the macroeconomic effects of forward guidance into two interesting additive components. The first component represents the sole effects of the change in expectations triggered by forward guidance. We call this component the expectation channel of forward guidance. The second component captures the effects of implementing the deviations by taking the private sector by surprise in every period. This is akin to the central bank opting not to communicate how it will deviate from its rule in the future. 
To evaluate the expectation channel, we construct a policy experiment in which the path of signals generated by the forward guidance shock is just noise. In this case expectations about the future deviations of monetary policy are the same as those discussed above under imperfect communications. This can be seen by inspecting equations (2) and (3). In addition, when forward guidance is noise-driven, the perfectly revealing signal for the contemporaneous deviation must be always equal to zero. This experiment captures the expectations channel of forward guidance because there are no actual policy deviations and so the only effects of forward guidance arise due to expectations that deviations will occur. The difference between the response of hours (or any other endogenous variable) due to the expectations channel and the overall response (the black lines in Figures 4 and 6) corresponds to the case where the central bank opts not to communicate its future deviations and conducts policy by surprising agents every time the deviations are implemented.

The yellow bars and blue bars in Figures 4 and 6 show the decomposition of the imperfect communications response of hours to the forward guidance shock into the expectations channel and the no communication components, respectively. The expectation channel heavily affects the propagation of forward guidance shocks and is most potent early on. In the second sample its effects dominate the response of hours in the first year and a half after the shock, but its intensity quickly diminishes thereafter. In the first sample the dynamics are similar but obviously more short-lived. The expectations channel dominates the response of hours over the first three quarters of guidance. Comparing the yellow with the blue bars demonstrates that the expectation channel makes the effects of monetary shocks more frontloaded. This suggests that forward-looking communications, even if imperfect, might be a useful tool to provide a buffer against perceived risks to the outlook.

\subsection{The effects of miscommunication}

Since they correspond to the effects of forward guidance driven by noise only, the yellow bars in Figures 4 and 6 capture situations in which either the central bank's communications are misinterpreted by the private sector or the central bank changes its mind about future deviations from the rule after it has announced them. The magnitude of the yellow bars suggests that such communications feed macroeconomic volatility and can challenge the 
central bank's ability to stabilize real activity and inflation (the latter is not shown). This highlights the benefits that might accrue to a central bank that invests in developing effective communications. It also helps to explain why central bankers are typically wary of what they say in public.

\section{Conclusion}

This paper measured the imperfect ability of the Fed to communicate forward guidance and the influence of its imperfect communications on private-sector expectations and macroeconomic outcomes. We found that the Fed's ability to affect expectations at horizons that are sufficiently long to give rise to the forward guidance puzzle is substantially limited. The difficulties inherent in communicating complicated decisions about the future path of interest rates may be too great for forward guidance to be the powerful instrument predicted by standard NK models. We also found that response of the economy to a shock that changes the anticipated path of policy deviations is delayed and has greater amplitude when communications are imperfect compared to when they are not.

We constructed a novel decomposition of the dynamic effects of forward guidance into the part solely due to the change in expectations it triggers and the effects that arise from a scenario in which the central bank opts not to communicate its future policy deviations. This decomposition shows that agents' expectations of future policy deviations pull forward the effects of those deviations significantly compared to not communicating at all. We argue that this suggests forward guidance, even if it is imperfectly communicated, could be a valuable tool for a central bank seeking to guard against perceived risks to the economic outlook. The decomposition also shows that unintended communication that contains no information about future policy deviations leads to sizable macroeconomic volatility. This result highlights the benefits that accrue to a central bank that invests in developing effective communications and helps to explain why central bankers are typically wary of what they say in public.

While our findings show clearly that the Fed has a limited ability to shape expectations it is not so limited as to suggest the Fed should eliminate forward guidance from its policy toolbox. We did find the power of forward guidance to be extremely limited in the period 
when the funds rate was far from the ELB. However we also found that in the period after 2008 the horizon over which the Fed could influence expectations grew substantially. We conjectured that this may be due to two factors. First, it is possible that the extreme economic conditions after 2008 may have led the public to pay more attention to the Fed than they did during more normal times. Second, it just may be easier to communicate when policy is constrained by the ELB.

Imperfect central bank communications seems ripe for further study. Perhaps the most important task ahead is endogenizing forward guidance and incorporating an explicit role for risk management. Still we think our framework has useful applications that are worth pursuing, including isolating episodes in which the Fed was best able to communicate its future intentions, investigating central bank communications in other economies, and determining how forward guidance shaped inflation and inflation expectations during their gradual decline toward $2 \%$. We have explored one strategy for empirically evaluating central bank communications but clearly there is room for other approaches. Recently Coibion, Gorodnichenko, and Weber (2019) have opened up a new and exciting area of research which uses an experimental approach to understand the effects of central bank communication. Finally, we have not investigated the welfare implications of trying to communicate forward guidance. Are such communications advisable? Some of our findings hint at an answer to this question but there is much more to be done here as well. 


\section{References}

Andrade, P., G. Gaballo, E. Mengus, and B. Mojon (2018). Forward guidance and heterogeneous beliefs. American Economic Journal: Macroeconomics. Forthcoming.

Angeletos, G.-M. and C. Lian (2018, September). Forward guidance without common knowledge. American Economic Review 108(9), 2477-2512.

Angeletos, G.-M. and A. Pavan (2007). Efficient use of information and social value of information. Econometrica 75(4), 1103-1142.

Auclert, A., M. Rognlie, and L. Straub (2018). The intertemporal Keynesian cross. Harvard manuscript.

Bianchi, F. and L. Melosi (2017). Constrained discretion and central bank transparency. Review of Economics and Statistics. Forthcoming.

Blanchard, O., J.-P. L'Huillier, and G. Lorenzoni (2013). News, noise and fluctuations: An empirical exploration. American Economic Review 103(7), 3045-3070.

Campbell, J., J. Fisher, A. Justiniano, and L. Melosi (2017). Forward guidance and macroeconomic outcomes since the financial crisis. NBER Macroeconomics Annual 2016 31, $283-357$.

Campbell, J. R., C. L. Evans, J. D. Fisher, and A. Justiniano (2012). Macroeconomic effects of Federal Reserve forward guidance. Brookings Papers on Economic Activity Spring, $1-54$.

Campbell, J. R. and J. P. Weber (2019). Discretion rather than rules: Equilibrium uniqueness and forward guidance with inconsistent optimal plans. Federal Reserve Bank of Chicago Working Paper 2018-14.

Chahrour, R. and K. Jurado (2018). News or noise? The missing link. American Economic Review 108(7), 1702-1736.

Christiano, L., M. Eichenbaum, and C. Evans (2005). Nominal rigidities and the dynamic effects of a shock to monetary policy. Journal of Political Economy 113(1), 1-45.

Coibion, O., Y. Gorodnichenko, and M. Weber (2019, January). Monetary policy communications and their effects on household inflation expectations. Working Paper 25482, National Bureau of Economic Research.

Cover, T. M. and J. A. Thomas (1991). Elements of Information Theory. New York: Wiley.

Del Negro, M., M. P. Giannoni, and C. Patterson (2015). The forward guidance puzzle. New York Fed working paper.

Eggertsson, G. B. and M. Woodford (2003). The zero bound on interest rates and optimal monetary policy. Brookings Papers on Economic Activity 2003(1), 139-211. 
Eusepi, S. and B. Preston (2010, July). Central bank communication and expectations stabilization. American Economic Journal: Macroeconomics 2(3), 235-71.

Evans, C., J. Fisher, F. Gourio, and S. Krane (2015). Risk management for monetary policy near the zero lower bound. Forthcoming, Brookings Papers on Economic Activity.

Farhi, E. and I. Werning (2017, March). Monetary policy, bounded rationality, and incomplete markets. Working Paper 23281, National Bureau of Economic Research.

Fisher, J. (2015, March-April). On the structural interpretation of the smets-wouters "risk premium" shock. Journal of Money, Credit and Banking 47(2-3), 511-516.

Gabaix, X. (2016). A behavioral New Keynesian model. NYU-Stern manuscript.

Gürkaynak, R., B. Sack, and E. Swanson (2005). Do actions speak louder than words? International Journal of Central Banking 1(1), 55-93.

Hagedorn, M., J. Luo, I. Manovskii, and K. Mitman (2019). Forward guidance. Journal of Monetary Economics.

Justiniano, A., G. E. Primiceri, and A. Tambalotti (2010a, March). Investment shocks and business cycles. Journal of Monetary Economics 57(2), 132-145.

Justiniano, A., G. E. Primiceri, and A. Tambalotti (2010b). Investment shocks and business cycles. Journal of Monetary Economics 57(2), 132 - 145.

Kaplan, G., B. Moll, and G. L. Violante (2018, March). Monetary policy according to hank. American Economic Review 108(3), 697-743.

Krishnamurthy, A. and A. Vissing-Jorgensen (2011). The effects of quantitative easing on interest rates: Channels and implications for policy. Brookings Papers on Economic Activity Fall, 215-265.

Krugman, P. R. (1998). It's baaack: Japan's slump and the return of the liquidity trap. Brookings Papers on Economic Activity Fall, 137-187.

Kuttner, K. N. (2001). Monetary policy surprises and interest rates: evidence rom the federal funds futures market. Journal of Monetary Economics 47, 523-544.

Laséen, S. and L. E. Svensson (2011). Anticipated alternative policy-rate paths in policy simulations. International Journal of Central Banking.

Leeper, E. and T. Zha (2003). Modest policy interventions. Journal of Monetary Economics 50(8), 1673-1700.

Maćkowiak, B. and M. Wiederholt (2009). Optimal sticky prices under rational inattention. American Economic Review 99(3), 769-803.

McKay, A., E. Nakamura, and J. Steinsson (2015). The power of forward guidance revisited. Columbia University manuscript. 
Melosi, L. (2014). Estimating models with dispersed information. American Economic Journal: Macroeconomics 6(1), 1-31.

Melosi, L. (2016). Signalling Effects of Monetary Policy. The Review of Economic Studies $84(2), 853-884$.

Michaillat, P. and E. Saez (2018). A New Kynesian model with wealth in the utility function. NBER Working Paper 24971.

Morris, S. and H. S. Shin (2002, December). Social value of public information. American Economic Review 92(5), 1521-1534.

Nakamura, E. and J. Steinsson (2018, 01). High-Frequency Identification of Monetary NonNeutrality: The Information Effect*. The Quarterly Journal of Economics 133(3), 12831330 .

Sims, C. A. (2003). Implications of rational inattention. Journal of Monetary Economics 50(3), 665-690.

Smets, F. and R. Wouters (2007). Shocks and frictions in US business cycles: A Bayesian DSGE approach. The American Economic Review 97(3), 586-606.

Woodford, M. (2003). Interest and Prices. Princeton, NJ: Princeton University Press.

Yi, K.-M. and J. Zhang (2017). Understanding global trends in long-run real interest rates. Economic Perspectives $41(2)$. 


\section{Appendix}

\section{A. The factor structure of news}

Since the deviations from the rule $\boldsymbol{\theta}_{t}$ are possibly correlated up to the $H$-th lag in our model, we allow news shocks in the observationally equivalent news representation to be correlated across horizons at a point in time. To capture this, we follow Campbell et al. (2017) and assume that a factor structure determines the cross-correlations among news shocks. Specifically, we assume

$$
\varepsilon_{R, t}^{j}=\alpha_{j} f_{t}^{\alpha}+\beta_{j} f_{t}^{\beta}+\psi_{i} \eta_{t},
$$

where the factors $f_{t}^{\alpha}$ and $f_{t}^{\beta}$ and factor loadings $\alpha_{i}$ and $\beta_{i}$ are scalars, $\eta_{t}$ is an $H \times 1$ column vector of shocks, and $\psi_{i}$ is a $1 \times H$ vector of coefficients that depend on the model's structural parameters and is described in Campbell et al. (2017). The factors and shocks have zero means and are independent and normally distributed. In matrix notation, we have

$$
\boldsymbol{\varepsilon}_{R, t}=\alpha f_{t}^{\alpha}+\beta f_{t}^{\beta}+\psi \eta_{t},
$$

where $\alpha=\left[\alpha_{0}, \ldots, \alpha_{H}\right]^{\prime}, \beta=\left[\beta_{0}, \ldots, \beta_{H}\right]^{\prime}$ and $\psi=\left[\psi_{0}^{\prime}, \ldots, \psi_{H}^{\prime}\right]^{\prime}$. Let $\Sigma_{\eta}=E\left(\eta_{t} \eta_{t}^{\prime}\right)$ denote the variance-covariance matrix of the idiosyncratic shocks, and $\sigma_{\alpha}^{2}\left(\sigma_{\beta}^{2}\right)$ denote the variance of $f_{t}^{\alpha}\left(f_{t}^{\beta}\right)$. Recall $\Sigma_{\varepsilon} \equiv E\left(\varepsilon_{R, t} \varepsilon_{R, t}^{\prime}\right)$. Our estimate of the variance-covariance matrix of news is then given by

$$
\begin{aligned}
\Sigma_{\varepsilon} & =E\left(\alpha f_{t}^{\alpha}+\beta f_{t}^{\beta}+\psi \eta_{t}\right)\left(\alpha f_{t}^{\alpha}+\beta f_{t}^{\beta}+\psi \eta_{t}\right)^{\prime} \\
& =\alpha \alpha^{\prime} \sigma_{\alpha}^{2}+\beta \beta^{\prime} \sigma_{\beta}^{2}+\psi \Sigma_{\eta} \psi^{\prime} .
\end{aligned}
$$

\section{B. Deriving the moments of the policy deviations from the news representation}

We now derive the first and second moments of $\boldsymbol{\theta}_{t}, \boldsymbol{\theta}_{t}\left|s_{t-1}, \boldsymbol{\theta}_{t}\right| s_{t}$ and $\boldsymbol{\theta}_{t}^{p}$. To this aim, it is useful to write the vector of signals in matrix notation as follows

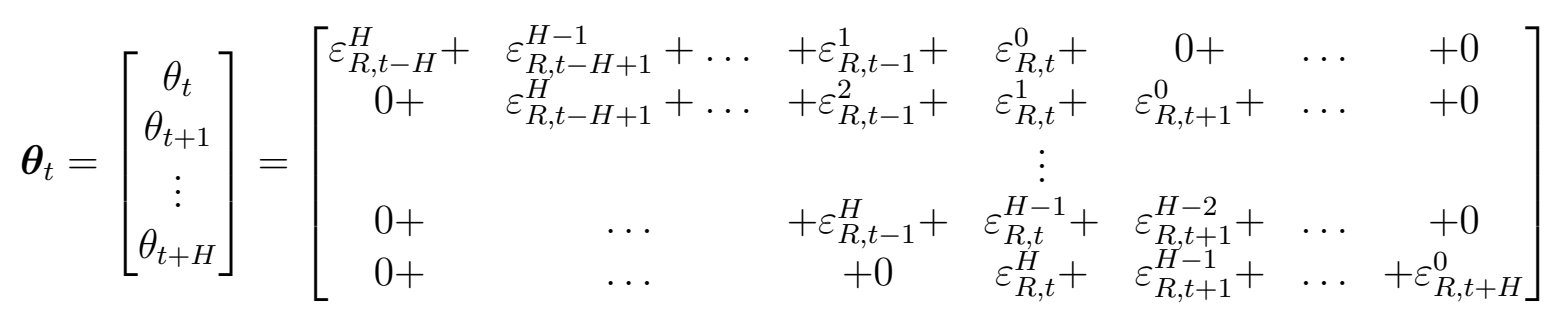

or equivalently

$$
\boldsymbol{\theta}_{t}=J_{H} \boldsymbol{\varepsilon}_{R, t+H}+\cdots+J_{1} \varepsilon_{R, t+1}+\boldsymbol{\varepsilon}_{R, t}+J_{1}^{\prime} \varepsilon_{R, t-1}+\cdots+J_{H}^{\prime} \varepsilon_{R, t-H},
$$


where $J_{k}$ is a $(H+1) \times(H+1)$ matrix of zeros with ones on the $k$ th lower diagonal; $J_{0}$ coincides with the identity matrix. For example, for when $H=4$ and $k=2$

$$
J_{2}=\left[\begin{array}{lllll}
0 & 0 & 0 & 0 & 0 \\
0 & 0 & 0 & 0 & 0 \\
1 & 0 & 0 & 0 & 0 \\
0 & 1 & 0 & 0 & 0 \\
0 & 0 & 1 & 0 & 0
\end{array}\right]
$$

We have that the first moments of $\boldsymbol{\theta}_{t}, \boldsymbol{\theta}_{t} \mid s_{t-1}$, and $\boldsymbol{\theta}_{t} \mid s_{t}$ are

$$
\begin{aligned}
E\left(\boldsymbol{\theta}_{t}\right) & =0 \\
E_{t-1}\left(\boldsymbol{\theta}_{t}\right) & =J_{1}^{\prime} \varepsilon_{R, t-1}+\cdots+J_{H}^{\prime} \boldsymbol{\varepsilon}_{R, t-H} \\
E_{t}\left(\boldsymbol{\theta}_{t}\right) & =E_{t-1}\left(\boldsymbol{\theta}_{t}\right)+\kappa\left(s_{t}-E_{t-1}\left(\boldsymbol{\theta}_{t}\right)\right) \\
& =E_{t-1}\left(\boldsymbol{\theta}_{t}\right)+\kappa\left(\boldsymbol{\theta}_{t}+v_{t}-E_{t-1}\left(\boldsymbol{\theta}_{t}\right)\right) .
\end{aligned}
$$

The corresponding second moments are given by

$$
\begin{aligned}
\Sigma_{\theta}= & E\left(\boldsymbol{\theta}_{t} \boldsymbol{\theta}_{t}^{\prime}\right) \\
= & J_{H} \Sigma_{\varepsilon} J_{H}^{\prime}+\cdots+J_{1} \Sigma_{\varepsilon} J_{1}^{\prime}+\Sigma_{\varepsilon}+J_{1}^{\prime} \Sigma_{\varepsilon} J_{1}+\cdots+J_{H}^{\prime} \Sigma_{\varepsilon} J_{H} \\
\Xi_{\theta}= & E\left(\boldsymbol{\theta}_{t}-E_{t-1}\left(\boldsymbol{\theta}_{t}\right)\right)\left(\boldsymbol{\theta}_{t}-E_{t-1}\left(\boldsymbol{\theta}_{t}\right)\right)^{\prime} \\
= & J_{H} \Sigma_{\varepsilon} J_{H}^{\prime}+\cdots+J_{1} \Sigma_{\varepsilon} J_{1}^{\prime}+\Sigma_{\varepsilon} \\
\tilde{\Xi}_{\theta}= & E\left(\boldsymbol{\theta}_{t}-E_{t}\left(\boldsymbol{\theta}_{t}\right)\right)\left(\boldsymbol{\theta}_{t}-E_{t}\left(\boldsymbol{\theta}_{t}\right)\right)^{\prime} \\
= & E\left[\boldsymbol{\theta}_{t}-E_{t-1}\left(\boldsymbol{\theta}_{t}\right)-\kappa\left(\boldsymbol{\theta}_{t}+v_{t}-E_{t-1}\left(\boldsymbol{\theta}_{t}\right)\right)\right]\left[\boldsymbol{\theta}_{t}-E_{t-1}\left(\boldsymbol{\theta}_{t}\right)-\kappa\left(\boldsymbol{\theta}_{t}+v_{t}-E_{t-1}\left(\boldsymbol{\theta}_{t}\right)\right)\right]^{\prime} \\
= & E\left[\boldsymbol{\theta}_{t}-E_{t-1}\left(\boldsymbol{\theta}_{t}\right)\right]\left[\boldsymbol{\theta}_{t}-E_{t-1}\left(\boldsymbol{\theta}_{t}\right)\right]^{\prime}+E\left[\kappa\left(\boldsymbol{\theta}_{t}+v_{t}-E_{t-1}\left(\boldsymbol{\theta}_{t}\right)\right)\right]\left[\kappa\left(\boldsymbol{\theta}_{t}+v_{t}-E_{t-1}\left(\boldsymbol{\theta}_{t}\right)\right)\right]^{\prime} \\
& -2 \times E\left[\boldsymbol{\theta}_{t}-E_{t-1}\left(\boldsymbol{\theta}_{t}\right)\right]\left[\kappa\left(\boldsymbol{\theta}_{t}+v_{t}-E_{t-1}\left(\boldsymbol{\theta}_{t}\right)\right)\right]^{\prime} \\
= & \Xi_{\theta}+\kappa\left(\Xi_{\theta}+\Xi_{v}\right) \kappa^{\prime}-2 \Xi_{\theta} \kappa^{\prime} \\
= & \Xi_{\theta}+\Xi_{\theta}\left(\Xi_{\theta}+\Xi_{v}\right)^{-1}\left(\Xi_{\theta}+\Xi_{v}\right)\left(\Xi_{\theta}+\Xi_{v}\right)^{-1} \Xi_{\theta}^{\prime}-2 \Xi_{\theta}\left(\Xi_{\theta}+\Xi_{v}\right)^{-1} \Xi_{\theta}^{\prime} \\
= & \Xi_{\theta}-\Xi_{\theta}\left(\Xi_{\theta}+\Xi_{v}\right)^{-1} \Xi_{\theta}^{\prime} .
\end{aligned}
$$

The last derivation uses the property of noise that $E\left[\boldsymbol{\theta}_{t}-E_{t-1}\left(\boldsymbol{\theta}_{t}\right)\right] v_{t}^{\prime}=0$.

Notice that we now have all the ingredients necessary to back out times series for $\boldsymbol{\theta}_{\boldsymbol{t}}$ and $v_{t}$ from the monetary policy news derived from the estimated model. We can obtain $\boldsymbol{\theta}_{\boldsymbol{t}}$ from (10) or (13). We can obtain $v_{t}$ using (7) combined with (14), our time series for $\boldsymbol{\theta}_{t}$, and our estimate of $\kappa$ that uses (4), (9), (12), and (15).

The derivations of the moments of the path of monetary policy, $\boldsymbol{\theta}_{t}^{p}=\left[\theta_{t+1}, \ldots, \theta_{t+H}\right]^{\prime}$, are quite straightforward as we just apply the previous calculations to a linear transformation of $\boldsymbol{\theta}_{t}$. In particular, we have the future path of monetary policy is given by

$$
\boldsymbol{\theta}_{t}^{p}=P \boldsymbol{\theta}_{t}
$$

where $P$ is the $H \times(H+1)$ matrix that removes the first element of the vector $\boldsymbol{\theta}_{t}$. First 
and second moments of $\boldsymbol{\theta}_{t}^{p}$ are then easy to derive. In particular,

$$
\Xi_{\theta}^{p}=E\left(P \boldsymbol{\theta}_{t}-E_{t-1}\left(P \boldsymbol{\theta}_{t}\right)\right)\left(P \boldsymbol{\theta}_{t}-E_{t-1}\left(P \boldsymbol{\theta}_{t}\right)\right)^{\prime}=P \Xi_{\theta} P^{\prime}
$$

The expected value of $\boldsymbol{\theta}_{t}^{p}$ conditional of having received the signals about the deviations from the policy rule from $H$ and until $H-h$ quarters out is given by

$$
\begin{aligned}
E\left(\boldsymbol{\theta}_{t}^{p} \mid s^{t-1}, s_{t}^{H}, s_{t}^{H-1} \ldots, s_{t}^{H-h}\right) & =E_{t-1}\left(\boldsymbol{\theta}_{t}^{p}\right)+\kappa_{h} S_{h}\left(s_{t}-E_{t-1}\left(\boldsymbol{\theta}_{t}^{p}\right)\right) \\
& =E_{t-1}\left(\boldsymbol{\theta}_{t}^{\boldsymbol{p}}\right)+\kappa_{h} S_{h}\left(\boldsymbol{\theta}_{t}^{p}+v_{t}-E_{t-1}\left(\boldsymbol{\theta}_{t}^{p}\right)\right)
\end{aligned}
$$

where $\kappa_{h}=\Xi_{\theta} S_{h}^{\prime}\left(S_{h}\left(\Xi_{\theta}+\Xi_{v}\right) S_{h}^{\prime}\right)^{-1}$ and $S_{h}$ is a $(h+1) \times H$ selection matrix that has ones on the right most diagonal and zeros elsewhere. For example, at the longest horizon when $h=0, S_{0}=[0,0, \ldots, 1]$. When $h=1$,

$$
S_{1}=\left[\begin{array}{llll}
0 & \ldots & 1 & 0 \\
0 & \ldots & 0 & 1
\end{array}\right] .
$$

We can derive the covariance matrix of $\boldsymbol{\theta}_{t}^{p}$ conditional of having received a subset of signal signals in the same way we derived $\tilde{\Xi}_{\theta}$. Doing so we obtain

$$
\Xi_{\theta, h}^{p}=\Xi_{\theta}^{p}-\Xi_{\theta}^{p} S_{h}^{\prime}\left(S_{h}\left(\Xi_{\theta}^{p}+\Xi_{v}\right) S_{h}^{\prime}\right)^{-1} S_{h} \Xi_{\theta}^{p} .
$$

\section{Decomposing Forward Guidance}

In the main text we claim that the signal representation allows us to decompose the dynamic response of an endogenous variable to a forward guidance shock into two additive components. The first component represents the sole effects of the change in expectations triggered by forward guidance (the yellow bars in Figures 4 and 6). The second component captures the effects of implementing the deviations implied by the forward guidance shocks without announcing them in advance (the blue bars in Figures 4 and 6). In this section we sketch the proof of this claim.

It is easier to work with the news representation of the model. Recall that the actual deviation from the rule at time $t$ is given by all the news about it received up until that date plus the contemporaneous news:

$$
\theta_{t}=\sum_{j=0}^{H} \varepsilon_{R, t-j}^{j} .
$$

The news are obtained from the signal representation by using (7).

The response of hours in the baseline case of truthful forward guidance (the black line in Figures 4 and 6) is obtained by assuming that the forward guidance shock is driven by actual future deviations from the rule (zero noise). The alternative scenario is obtained by simulating the news representation with the contemporaneous news $\varepsilon_{R, t}^{0}$ replaced by $\tilde{\varepsilon}_{R, t}^{0}$ where

$$
\tilde{\varepsilon}_{R, t}^{0} \equiv-\sum_{j=1}^{H} \varepsilon_{R, t-j}^{j},
$$


for every $t$. In the alternative scenario with forward guidance driven by noise the contemporaneous news shock must neutralize the effects of all the news about the date $t$ deviation in the previous $H$ periods. Imposing (17) guarantees this. The remaining news shocks are the same in both the baseline case and in the alternative scenario.

The infinite moving average representation of hours in our model, $h_{t}$, can be expressed as

$$
h_{t}=\Phi(L) \xi_{t}
$$

where $\xi_{t}$ is the column vector containing all the shocks realized at time $t$. We order the shocks in $\xi_{t}$ such that the news shocks realized at date $t$ are ordered first. The blue bars in Figures 4 and 6 are constructed by taking the difference between the response of hours to news shocks in the baseline $\left(h_{t}\right)$, the black line, and in the alternative scenario of noise-driven forward guidance $\left(\tilde{h}_{t}\right)$, the yellow bars. Specifically,

$$
\begin{aligned}
h_{t}-\tilde{h}_{t} & =\Phi_{h}(L)\left[\begin{array}{c}
\varepsilon_{R, t}^{0}-\tilde{\varepsilon}_{R, t}^{0} \\
\mathbf{0}
\end{array}\right] \\
& =\Phi_{h}(L)\left[\begin{array}{c}
\varepsilon_{R, t}^{0}+\sum_{j=1}^{H} \varepsilon_{R, t-j}^{j} \\
\mathbf{0}
\end{array}\right] \\
& =\Phi_{h}(L)\left[\begin{array}{c}
\theta_{t} \\
\mathbf{0}
\end{array}\right],
\end{aligned}
$$

where in the first line we use the infinite moving average representation of hours, the second line is obtained by plugging equation (17), and the third line stems from equation (16).

It follows that the difference in hours between the baseline case and the alternative scenario, $h_{t}-\tilde{h}_{t}$, can be obtained by simulating the news representation using the actual deviations from the rule $\theta_{t}$ as contemporary news shocks and without any other news. This scenario is tantamount to the case of no communication in which the central bank does not say anything about its future deviations and it just implements them over time. 